Wirtschaftswissenschaftliches Zentrum (WWZ) der Universität Basel

$\mathrm{WW} \mid \mathrm{Z}$

December 2011

\title{
Internal Rent Seeking, Works Councils, and Optimal Establishment Size
}


The Authors:

\section{Prof. Dr. Michael Beckmann}

Department of Human Resources and Organization (WWZ), University of Basel

Peter Merian-Weg 6

CH - 4002 Basel

Phone: +41612673224

michael.beckmann@unibas.ch

\section{Prof. Dr. Matthias Kräkel}

Department of Personnel and Organizational Economics, University of Bonn

Adenauerallee 24 - 42

D-53113 Bonn

Phone: +49228 733914

m.kraekel@uni-bonn.de

A publication of the Center of Business and Economics (WWZ), University of Basel.

(C) The author(s). Reproduction for other purposes than the personal use needs the permission of the author(s).

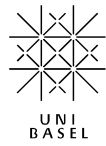




\title{
Internal Rent Seeking, Works Councils, and Optimal Establishment Size*
}

\author{
Michael Beckmann ${ }^{\dagger} \quad$ Matthias Kräkel ${ }^{\ddagger}$
}

\begin{abstract}
Using a microeconomic model and data from the Establishment Panel of the German Institute for Employment Research, we analyze the optimal establishment size against the background of rent-seeking workers and the influence of works councils. The theoretical part shows that establishment size has a discouragement effect on the level of individual rent seeking but also a quantity effect as the number of rent seekers increases. The interplay of both effects - together with technological considerations - determines whether the employer chooses an inefficiently small or large establishment size. Introduction of a works council restores efficient establishment size although it is purely used as rent-seeking device. Whether the employer benefits from a works council or not, depends on the degree of contract incompleteness and the degree of worker coordination via a works council. The empirical part indicates dominance of the discouragement effect over the quantity effect in establishments without works council. As theoretically predicted, works councils are beneficial by disentangling rent-seeking and production issues, thus eliminating the influence of the two rent-seeking effects.
\end{abstract}

Key Words: establishment size; rent-seeking; works council

JEL Classification: J51, J52, J53, L25.

*We would like to thank Oliver Fabel, Bernd Fitzenberger, Oliver Gürtler, Christian Laux, Dirk Sliwka and two anonymous referees for helpful comments. The data base of this paper is the IAB Establishment Panel, waves 2001-2008. The data access has been carried out via a controlled teleprocessing at the FDZ (Research Data Centre of the German Federal Employment Agency (BA) at the Institute for Employment Research (IAB)). Financial support by the Deutsche Forschungsgemeinschaft (DFG), grant SFB/TR 15, is gratefully acknowledged.

†University of Basel, Peter Merian-Weg 6, CH-4002 Basel, Switzerland, tel: +41 6126732 24, fax: +4161 26727 58, e-mail: Michael.Beckmann@unibas.ch.

${ }_{\ddagger}^{\ddagger}$ University of Bonn, Adenauerallee 24-42, D-53113 Bonn, Germany, tel: +49 2287339 14, fax: +492287392 10, e-mail: m.kraekel@uni-bonn.de. 


\section{Introduction}

The effort exerted by organization members to maximize their expected utility may often not only be productive but also counterproductive. Such behavior typically aims at redistributing organizational rents and can therefore be labeled internal rent seeking (e.g., Gibbons 2005). The problem of internal rent seeking arises from the fact that contractual relationships are usually incomplete (Masten 1986, Konrad 2002), which particularly holds for labor contracts (Simon 1951). This incompleteness leaves room for politicking and influence activities that cannot be prevented by law or formal contracts. Internal rent seeking does not only occur among the workers of an establishment but also between workforce and employer. As has been emphasized by Freeman and Lazear (1995), the workforce strictly benefits from a works council when competing for rents with the employer.

The aim of our paper is twofold. First, we theoretically analyze the employer's optimal choice of establishment size when workers invest in rent seeking and possibly install a works council. The analysis proceeds in two steps. In a first step, optimal establishment size is derived in a situation where workers cannot rely on a works council when competing with their employer for internal rents. In this benchmark case, one might presume that the employer is interested to limit the rent-seeking problem by reducing establishment size and, hence, the number of internal rent seekers (Holmström and Roberts 1998, p. 77). This aspect will be referred to as the quantity effect. However, there also exists a discouragement effect for rent seekers if the number of opponents becomes large, because individual rent seeking has a lower relative weight. In practice, moreover, the employer does not determine establishment size solely to control rent-seeking behavior. He will also be concerned with technological issues when choosing the optimal number of workers. The smaller the degree of contractual incompleteness, the more emphasis the employer will put on production technology. We discuss how these three effects interact and influence the employer's choice of establishment size.

In a second step, we introduce a works council into the game, which is a body installed by the workforce of an establishment. ${ }^{1}$ A works council - loosely compa-

\footnotetext{
${ }^{1}$ See Addison (2009) for a comprehensive survey.
} 
rable to a local union ${ }^{2}$ - serves as an institutional voice for the workers (Hirschman 1970), thus improving the establishment's suggestion system and saving bargaining costs by replacing individual bargaining by collective bargaining. However, this instrument can also be used by the workforce as a pure rent-seeking device (e.g., Freeman and Lazear 1995). Works councils are quite common, particularly in the countries of the European Union, where some national labor laws even stipulate mandatory councils (e.g., the Works Constitution Act [Betriebsverfassungsgesetz] in Germany). ${ }^{3}$ Installing a works council allows the workers to coordinate individual behavior. This coordination enables the workforce to act as a single collective player against the employer in the internal rent-seeking contest and, hence, prevents workers from competing against each other. The impact of a works council on overall rent seeking is analyzed, referring again to the quantity and the discouragement effects.

The second aim of our paper is to empirically test the relevance both of the discouragement and the quantity effects for overall rent seeking and the impact of a works council on these two effects. Using data from an establishment-level survey, we investigate these two rent-seeking effects both of which correspond to establishment size. From a theoretical viewpoint the impact of establishment size on overall rent seeking is ambiguous: according to the quantity effect, rent seeking should be increasing in establishment size, whereas dominance of the discouragement effect should lead to a negative relationship. Hence, the crucial question as to which effect is more relevant in practice can only be answered empirically.

However, the theoretical model yields a clear-cut prediction concerning the influence of a works council on the two rent-seeking effects. Since a works council acts on the authority of the complete workforce, the number of workers is no longer decisive for rent seeking. A works council thus eliminates the discouragement and quantity effects so that we do not expect a significant effect of establishment size on the intensity of overall rent seeking. Note that this general result regarding the disentangling of rent-seeking and production issues by the introduction of a

\footnotetext{
${ }^{2}$ Of course, there are also institutional differences between works councils and local unions. For example, works councils are typically not allowed to organize a strike of the workforce and do not directly bargain over wages.

${ }^{3}$ For an overview, see Rogers and Streeck (1995).
} 
collective representative of the workers also applies to local unions.

The findings of our econometric model show that the discouragement effect is highly relevant for rent seeking in establishments without a works council. Establishment size has a significantly negative effect on overall rent-seeking intensity, thus indicating that individual rent seekers are discouraged if the number of coworkers increases. The results also indicate that works councils tend to intensify the workers' rent-seeking activities by eliminating the discouragement effect. Our empirical findings support the theoretical model: whereas the discouragement effect has a significant influence on establishments without a works council, neither rent-seeking effect has a significant influence on establishments with a works council.

The paper is organized as follows. The next section gives an overview of the related literature. Section 3 introduces the basic theoretical model. Section 4 addresses the relationship between internal rent seeking and optimal establishment size without a works council. In Section 5, we introduce a works council in our game and analyze the implications for optimal establishment size, the employer's rent-seeking expenditures, and establishment profits. Section 6 contains our econometric analysis. Section 7 concludes.

\section{Related Literature}

Our paper is related to two fields of the economic literature - the discussion of works councils and the work on internal rent-seeking contests. There exists one seminal theory article in the field of works councils, namely the paper by Freeman and Lazear (1995). ${ }^{4}$ For this reason, our paper makes an attempt to fill the theory gap in the research on works councils. The economic analysis of Freeman and Lazear (1995) points out that mandated works councils can be welfare improving. Given a rent-seeking scenario between employer and workforce, the employer would choose an inefficiently small degree of employee involvement, while the workforce would choose an inefficiently large degree of employee involvement in order to increase its power when competing with the employer for internal rents. Therefore,

\footnotetext{
${ }^{4}$ See also Addison (2009), pp. 33-35, on the Freeman-Lazear approach.
} 
a mandated works council with a moderate degree of employee involvement can be a better solution from society's point of view. Moreover, Freeman and Lazear show that better communication via a works council can also increase welfare. Our paper is related to the first part of Freeman and Lazear (1995) on works councils as a rent-seeking instrument. In contrast to Freeman and Lazear (1995), we use a contest model to analyze the game between the employer and the workers with and without a works council to compare both outcomes. Moreover, we focus on establishment size, which influences establishment performance because of the technological issues and rent-seeking effects involved.

Many empirical papers on works councils investigate, whether welfare and establishment performance (e.g., profits, labor turnover, productivity, innovations) are positively or negatively related to the existence of a works council. ${ }^{5}$ Addison et al. (2000) directly test the Freeman-Lazear approach, using data from Britain (where works councils are not mandated) and Germany (with mandatory works councils). They find that the data offer empirical support for the key results of the Freeman-Lazear model. But altogether, the empirical studies offer mixed results. For example, Fitzroy and Kraft (1987) find that works councils are negatively associated with establishment productivity. However, other studies observe positive or at least no negative productivity effects of works councils (e.g., Addison et al. 2006, Mueller 2009). In our model, we address the reversed question of how productivity affects the behavior of a works council. We show that higher productivity leads to a larger rent and, thus, to more intense rent seeking by the works council.

Since both employer and workers invest in labor relationships and generate quasi-rents, a works council may not only engage in rent seeking to hold-up the employer (in cases where the employer is the investor) but also in rent protection (in cases where workers are the investing party). Whereas the findings of Beckmann et al. (2010) support the rent-seeking hypothesis, Jirjahn (2009) provides evidence on the second aspect of works councils. He shows that workers often introduce works councils in difficult economic situations in order to protect their investments in human capital and in internal careers in the form of high effort levels. In a sense, this view of rent protection complements the view taken in our paper on works

\footnotetext{
${ }^{5}$ See Addison (2009), chaps. 4-6, for a more comprehensive overview of the empirical literature on works councils.
} 
councils as a rent-seeking device.

The second field of related literature deals with internal rent-seeking contests in organizations. Konrad (2004) emphasizes that organizing rent-seeking conflicts within a hierarchy may imply lower overall rent-seeking expenditures. Inderst et al. (2007) show that multi-divisional organizations may suffer less from internal rent seeking than single-tier organizations, although each division exhibits a rent-seeking contest. Kräkel (2008) shows that efficient and highly profitable establishments may not be founded because of the anticipated excessive rent seeking that will follow. The three papers mentioned relate internal rent seeking to the organizational structure or the founding of a firm, respectively, but none focuses on the impact of establishment size on rent-seeking intensity nor on the role of works councils or local unions.

\section{The Basic Theoretical Model}

We consider an establishment with a single employer $E$ and $N \geq 2$ workers. Establishment size $N$ is endogenous and optimally chosen by $E$. By employing $N$ workers, $E$ realizes profit

$$
\pi(N)=\theta \cdot Y(N)-w \cdot N
$$

where the exogenous productivity parameter $\theta>0$ characterizes the economic situation of the establishment, $Y(N)$ is strictly concave (with $Y^{\prime}(N) \geq 0$ and $\left.Y^{\prime \prime}(N)<0\right)$ describing the establishment's production function, and $w>0$ stands for a worker's exogenously given wage rate, which just covers his disutility of effort. ${ }^{6}$ Note that $Y(N)$ only describes production at the aggregate establishment level. At the disaggregate level, our setting allows (i) workers to differ in individual abilities, (ii) efforts and abilities to be either complements or substitutes, and (iii) different workers to be either complements or substitutes in production. However, aggregate establishment output can be described by the concave function $Y(N)$. The function $\pi(N)$ is assumed to have an interior maximum. Moral

\footnotetext{
${ }^{6}$ Hence, $w$ has to be paid to the workers in any case and cannot be offset against anticipated benefits from internal rent seeking.
} 
hazard problems regarding the establishment's production are excluded.

Internal relationships are not completely covered by explicit contracts. Only the fraction $\alpha \in(0,1)$ of the profit is contractually guaranteed to $E$, whereas, due to incomplete contracting, $(1-\alpha) \pi(N)$ is distributed among the $N$ workers and the employer via internal rent seeking. ${ }^{7}$ Thus, $1-\alpha$ can be interpreted as a measure for contract incompleteness. In the rent-seeking contest, each worker $i$ $(i=1, \ldots, N)$ and employer $E$ spend resources $a_{j} \geq 0(j=1, \ldots, N, E)$ such as valuable time to increase their individual shares in $(1-\alpha) \pi(N)$. These resource investments are given in monetary terms. We follow the rent-seeking technology suggested by Skaperdas (1996) and assume that player $j(j=1, \ldots, N, E)$ has a positive increasing and concave function $f(\cdot)$ that measures the impact of resource expenditures on the distribution of the rent $(1-\alpha) \pi(N)$. Moreover, we assume that the function $f(\cdot) / f^{\prime}(\cdot)$ is convex. ${ }^{8}$ Occasionally, we will refer to the family of power functions

$$
f(a)=\frac{a^{\beta}}{\beta} \text { with } \beta \leq 1
$$

as a well-known example of a concave impact function.

Typically, the employer and the workers have different rent-seeking possibilities. For example, $E$ can use his formal and informal authority, whereas the workers may threaten to withdraw future cooperation with $E$ and newly hired outsiders (e.g., in connection with internal knowledge transfer). ${ }^{9}$ We therefore assume that worker $i$ 's impact is given by $f\left(a_{i}+\tau_{i}\right)(i=1, \ldots, N)$ and that of employer $E$ by $f\left(a_{E}+\Delta\right)$ where $\Delta \geq 0$ indicates $E$ 's strength in the rent-seeking contest relative to the workers. Workers are allowed to be heterogeneous players in the rent-seeking game. $\tau_{i} \geq 0$ characterizes worker $i$ 's exogenous talent in asserting himself in the contest. The larger $\tau_{i}$, the larger is $i$ 's individual rent-seeking talent. ${ }^{10}$ To sum up, using the contest-success function of Skaperdas (1996), worker $i$ 's share in

\footnotetext{
${ }^{7}$ See, e.g., Konrad (2002) and Gibbons (2005) on rent-seeking due to incomplete contracts.

${ }^{8}$ See also Inderst et al. (2007, p. 390) on this assumption. Nti (1997, p. 52) considers the power, rational, logarithmic, and exponential functions as examples, all of which satisfy the convexity assumption.

${ }^{9}$ This problem has already been addressed by the insider-outsider approach introduced by Lindbeck and Snower $(1987,1988)$.

${ }^{10}$ Note that rent-seeking talents do not necessarily correspond to individual talents in production.
} 
$(1-\alpha) \pi(N)$ is given by $s_{i}\left(a_{i}\right)$ and that of employer $E$ by $s_{E}\left(a_{E}\right)$ with

$$
s_{i}\left(a_{i}\right)=\frac{f\left(a_{i}+\tau_{i}\right)}{F} \text { and } s_{E}\left(a_{E}\right)=\frac{f\left(a_{E}+\Delta\right)}{F}
$$

and $F:=f\left(a_{E}+\Delta\right)+\sum_{j=1}^{N} f\left(a_{j}+\tau_{j}\right)$. Worker $i(i=1, \ldots, N)$ maximizes utility

$$
u_{W i}\left(a_{i}\right)=(1-\alpha) \pi(N) \frac{f\left(a_{i}+\tau_{i}\right)}{F}-a_{i}
$$

and employer $E$ maximizes

$$
u_{E}\left(N, a_{E}\right)=\alpha \pi(N)+(1-\alpha) \pi(N) \frac{f\left(a_{E}+\Delta\right)}{F}-a_{E} .
$$

The game consists of the following five stages: (1) First, nature chooses the economic situation of the establishment, $\theta$, which becomes publicly observable. (2) Employer $E$ hires $N$ workers depending on the economic situation and the anticipated behavior in the rent-seeking contest. (3) Establishment size $N$ determines establishment output $Y(N)$ and, therefore, profit $\pi(N)$. (4) The $N$ workers and employer $E$ choose their optimal levels of rent-seeking expenditures, $a_{j}(j=1, \ldots, N, E)$. (5) Finally, each individual receives his payoff.

\section{Optimal Establishment Size without a Works Council}

Before solving the game via backwards induction, the first-best outcome is derived as a benchmark solution. Under first-best conditions, we have no contractual problems. In particular, there is no contractual incompleteness so that $\alpha=1$. In this situation, individuals maximize welfare by optimally choosing the first-best level of rent-seeking activities $a_{j}^{F B}=0=: a^{F B}(j=1, \ldots, N, E)$. The first-best establishment size, $N^{F B}$, then maximizes profit $\pi(N)$ implying

$$
\pi^{\prime}\left(N^{F B}\right)=0 \Leftrightarrow \theta \cdot Y^{\prime}\left(N^{F B}\right)=w .
$$


The first-best establishment size thus equalizes the value of marginal product and marginal labor costs.

Under the incomplete-contract setting described in Section 3, we have $\alpha<1$ so that this solution is not achieved. In stage 4 of the game, worker $i$ 's optimal rent seeking is given by the first-order condition ${ }^{11}$

$$
\frac{(1-\alpha) \pi(N)}{F^{2}}=\frac{1}{f^{\prime}\left(a_{i}+\tau_{i}\right)\left[f\left(a_{E}+\Delta\right)+\sum_{j \neq i}^{N} f\left(a_{j}+\tau_{j}\right)\right]}
$$

Note that the first-order condition of any other worker $k \neq i$ yields

$$
\frac{(1-\alpha) \pi(N)}{F^{2}}=\frac{1}{f^{\prime}\left(a_{k}+\tau_{k}\right)\left[f\left(a_{E}+\Delta\right)+\sum_{j \neq k}^{N} f\left(a_{j}+\tau_{j}\right)\right]} .
$$

Employer E's optimal rent-seeking expenditures are described by

$$
\frac{(1-\alpha) \pi(N)}{F^{2}}=\frac{1}{f^{\prime}\left(a_{E}+\Delta\right) \sum_{j=1}^{N} f\left(a_{j}+\tau_{j}\right)} .
$$

Combining the two workers' first-order conditions gives

$$
\frac{f\left(a_{i}+\tau_{i}\right)+F_{-i k}}{f^{\prime}\left(a_{i}+\tau_{i}\right)}=\frac{f\left(a_{k}+\tau_{k}\right)+F_{-i k}}{f^{\prime}\left(a_{k}+\tau_{k}\right)}
$$

with $F_{-i k}:=F-f\left(a_{i}+\tau_{i}\right)-f\left(a_{k}+\tau_{k}\right)$. Since both sides of the equation describe the same monotonically increasing function of $a_{i}+\tau_{i}$ or $a_{k}+\tau_{k}$, respectively, we have $a_{i}+\tau_{i}=a_{k}+\tau_{k}$ in equilibrium. Hence, if worker $i$ has a comparative advantage in internal rent seeking (i.e., $\tau_{i}>\tau_{k}$ ), he will use it to save expenditures as he invests less than his opponent $k$; otherwise $i$ spends more than $k$ to avoid falling behind his opponent in the contest. This relation holds for any pair of workers, yielding a clear ranking of equilibrium efforts. Combining worker $i$ 's first-order condition with that of the employer leads to $\left[f\left(a_{i}+\tau_{i}\right)+\sum_{j \neq i}^{N} f\left(a_{j}+\tau_{j}\right)\right] / f^{\prime}\left(a_{i}+\tau_{i}\right)=$ $\left[f\left(a_{E}+\Delta\right)+\sum_{j \neq i}^{N} f\left(a_{j}+\tau_{j}\right)\right] / f^{\prime}\left(a_{E}+\Delta\right)$. By the same argument as before, we see that $a_{E}+\Delta=a_{i}+\tau_{i}$.

We obtain that, in equilibrium, worker $i$ spends $a_{i}^{*}=a^{*}-\tau_{i}$ and the employer

\footnotetext{
${ }^{11}$ The second-order condition is satisfied.
} 
$a_{E}^{*}=a^{*}-\Delta$ with

$$
a^{*}=A\left(\frac{N(1-\alpha) \pi(N)}{(1+N)^{2}}\right)
$$

where $A$ denotes the inverse function of $f(x) / f^{\prime}(x)$. Note that $A$ is monotonically increasing since $f(x) / f^{\prime}(x)$ is increasing. Moreover, function $A$ is concave because $f(x) / f^{\prime}(x)$ is convex by assumption. Each player $j(j=1, \ldots, N, E)$ invests more in rent seeking the larger the rent $(1-\alpha) \pi(N)$, or - in other words - the higher the discretionary part of the profit, $1-\alpha$. For a given rent $(1-\alpha) \pi(N)=$ : $\bar{\pi}$ each player spends fewer resources the larger the number of contestants, $N$ (i.e., $\left.\partial A\left(N \bar{\pi} /(1+N)^{2}\right) / \partial N<0\right)$. This effect can be called discouragement effect since the relative impact of individual investment decreases in the number of opponents behaving in the same way. ${ }^{12}$ However, here the rent itself is a function of $N$ that increases (decreases) in $N$ as long as $N<(>) N^{F B}$, which can either mitigate or strengthen the discouragement effect.

Now we can solve the second stage of the game, where employer $E$ has to decide on optimal establishment size. E maximizes

$$
u_{E}\left(N, a_{E}^{*}\right)=\alpha \pi(N)+\frac{(1-\alpha) \pi(N)}{1+N}-A\left(\frac{N(1-\alpha) \pi(N)}{(1+N)^{2}}\right)+\Delta
$$

The employer's objective function shows that, on the one hand, $E$ may profit from the discouragement effect by choosing a large $N$, which serves as a self-commitment device ensuring that only a small amount of resources is spent at the contest stage, thus reducing rent-seeking costs in equilibrium. On the other hand, the expression $(1-\alpha) \pi(N) /(1+N)$ points to an opposite effect that makes choosing a low $N$ more attractive to the employer. For a given rent $(1-\alpha) \pi(N)$, the larger the number of rent-seeking workers, $N$, the smaller will be the employer's share in the rent (quantity effect). Altogether, when choosing optimal establishment size, the employer has to trade off the discouragement and the quantity effect against the direct effect of $N$ on profit $\pi(N)$. From the first-order condition we obtain the following result: ${ }^{13}$

\footnotetext{
${ }^{12}$ See also Nti (1997), p. 48; Wärneryd (2001), p. 325.

${ }^{13}$ Although $N$ is a positive integer, it is, for simplicity, treated as a continuous variable. To guarantee an interior solution, we assume that the second-order conditon is satisfied, which can only be checked for concrete specifications (consider, e.g., $f(a)=a, Y(N)=N^{\frac{1}{2}}, \alpha=0.9$,
} 
Proposition 1 E chooses establishment size $N^{*}$ implicitly described by

$$
\begin{aligned}
& \alpha \pi^{\prime}\left(N^{*}\right)=\frac{1-\alpha}{1+N^{*}}\left[\left(\frac{\pi\left(N^{*}\right)}{1+N^{*}}-\pi^{\prime}\left(N^{*}\right)\right)\right. \\
& \left.-A^{\prime}\left(\frac{(1-\alpha) \pi\left(N^{*}\right) N^{*}}{\left(1+N^{*}\right)^{2}}\right)\left(\frac{\pi\left(N^{*}\right)\left(N^{*}-1\right)}{\left(1+N^{*}\right)^{2}}-\frac{\pi^{\prime}\left(N^{*}\right) N^{*}}{\left(1+N^{*}\right)}\right)\right] .
\end{aligned}
$$

Recall that the first-best establishment size is defined by $\pi^{\prime}\left(N^{F B}\right)=0$ according to (6). Hence, since $\pi(N)$ is a strictly concave function with an interior maximum, we will have $N^{*}<(>) N^{F B}$ if the right-hand side of (7) is positive (negative). From the discussion above we know that the first term in square brackets, $\frac{\pi\left(N^{*}\right)}{1+N^{*}}-\pi^{\prime}\left(N^{*}\right)$, characterizes the quantity effect, whereas the second term, $-A^{\prime}\left(\frac{(1-\alpha) \pi\left(N^{*}\right) N^{*}}{\left(1+N^{*}\right)^{2}}\right)\left(\frac{\pi\left(N^{*}\right)\left(N^{*}-1\right)}{\left(1+N^{*}\right)^{2}}-\frac{\pi^{\prime}\left(N^{*}\right) N^{*}}{\left(1+N^{*}\right)}\right)$, indicates the discouragement effect. To illustrate the impact of both effects, imagine for a moment that both expressions, $\frac{\pi(N)}{1+N}-\pi^{\prime}(N)$ and $\frac{\pi(N)(N-1)}{(1+N)^{2}}-\frac{\pi^{\prime}(N) N}{(1+N)}$ are positive for all values of $N{ }^{14}$ In that case, the quantity effect would favor an inefficiently small establishment size from $E$ 's point of view since his share in the rent decreases in the number of rent-seekers. However, according to the discouragement effect, $E$ would prefer an inefficiently large establishment size to undermine the competition at the rent-seeking stage. Whether the quantity effect dominates the discouragement effect or vice versa, depends on the underlying contest-success function as well as the underlying production technology $Y(N)$ that determines $\pi(N)$. Referring to the family of power impact functions characterized by (2) leads to the following clear-cut result: ${ }^{15}$

Corollary 1 If the impact function is described by (2), then $N^{*}<N^{F B}$.

The corollary shows that combining the so-called logit-form contest-success function described by (3) with the family of power impact functions (2) unambiguously leads to a dominance of the quantity effect relative to the discouragement effect. However, the findings in Kräkel (2008) indicate that such dominance does not necessarily hold for other contest-success functions such as the probit model.

$w=0.2$, and $\theta=1)$.

${ }^{14}$ Note that concavity of the profit function only guarantees that $\pi(N) / N>\pi^{\prime}(N)$. However, we can think of concrete specifications for which both expressions are indeed always positive; e.g., we can again use $Y(N)=N^{\frac{1}{2}}, w=0.2$ and $\theta=1$.

${ }^{15}$ The proofs of Corollary 1 and the following propositions are relegated to the appendix. 
Before we switch to the case of a works council, we can finally investigate the influence of the economic situation, indicated by $\theta$, on optimal establishment size and rent-seeking behavior. For illustrating purposes, we again refer to the family of power impact functions. The following result can be derived:

Proposition 2 Let the impact function be described by (2). If $\frac{Y\left(N^{*}\right)}{1+N^{*}}<Y^{\prime}\left(N^{*}\right)$ and $\beta$ is smaller than a certain cut-off value $\bar{\beta}\left(N^{*}\right)$, then $\partial N^{*} / \partial \theta>0$. Otherwise, there will exist a cut-off value $\bar{\alpha}$ so that $\alpha>\bar{\alpha}$ implies $\partial N^{*} / \partial \theta>0$.

The proof of Proposition 2 shows that

$$
\frac{\partial N^{*}}{\partial \theta}=\frac{\alpha Y^{\prime}\left(N^{*}\right)-\frac{1-\alpha}{1+N^{*}}\left[\left(\frac{Y\left(N^{*}\right)}{1+N^{*}}-Y^{\prime}\left(N^{*}\right)\right)-\beta\left(\frac{Y\left(N^{*}\right)\left(N^{*}-1\right)}{\left(1+N^{*}\right)^{2}}-\frac{Y^{\prime}\left(N^{*}\right) N^{*}}{\left(1+N^{*}\right)}\right)\right]}{-\partial^{2} u_{E}\left(N^{*}, a_{E}^{*}\right) / \partial N^{* 2}} .
$$

Since the denominator is positive, the sign of $\partial N^{*} / \partial \theta$ is identical to that of the numerator. There are three effects that determine the sign. The first effect refers to $\alpha Y^{\prime}\left(N^{*}\right)=\frac{\partial \pi^{\prime}\left(N^{*}\right)}{\partial \theta}>0$ and can be labeled productivity effect: the larger $\theta$ the more productive will be the underlying production technology, which favors increasing output by enlargement of $N^{*}$. The expression in square brackets describes the interplay of the two other effects - the discouragement effect and the quantity effect - analogously to the term in square brackets in (7). This expression can be either positive or negative.

If power parameter $\beta$ is sufficiently small, the impact of the discouragement effect will diminish, but the employer may nevertheless increase $N^{*}$. In light of the discussion of the discouragement effect above, this finding seems odd at first sight as $E$ 's resource expenditures decrease in $N$ in equilibrium. However, note that the condition $Y^{\prime}\left(N^{*}\right)>\frac{Y\left(N^{*}\right)}{1+N^{*}}$ characterizes a situation where productivity is quite large. In that case, the overall impact of the production technology will dominate rent-seeking issues: Productivity is so large that the employer will unambiguously increase production despite the fact that part of it will be lost in the rent-seeking contest and that the quantity effect exacerbates the problem, the larger $N^{*}$. Technically, both expressions in the numerator of $\partial N^{*} / \partial \theta$ will be positive $-\alpha Y^{\prime}\left(N^{*}\right)$ immediately according to the productivity effect as well as the remainder of the numerator due to $Y^{\prime}\left(N^{*}\right)>\frac{Y\left(N^{*}\right)}{1+N^{*}}$ and $\beta<\bar{\beta}\left(N^{*}\right)$. Since the production function 
$Y(N)$ is concave, the presence of a rather high productivity will primarily apply to relatively small establishments. Consider, for example, $Y(N)=N^{\delta}$ with $\delta \leq 1$ so that $Y^{\prime}\left(N^{*}\right)>\frac{Y\left(N^{*}\right)}{1+N^{*}} \Leftrightarrow \delta>\frac{N^{*}}{1+N^{*}}$. Hence, the described situation will be relevant if, for a given optimal number of workers, the production technology is not too concave or if, for a given production technology, the optimal number of workers is not too large.

If the expression in square brackets in the numerator of $\partial N^{*} / \partial \theta$ is positive, the sign of $\partial N^{*} / \partial \theta$ will depend on whether production issues are more important than rent-seeking problems. If the discretionary part of the profit is sufficiently small (i.e., $\alpha>\bar{\alpha}$ ), the productivity effect will dominate rent-seeking issues, and the employer will prefer to increase establishment size. Of course, this will also increase the number of internal rent-seekers, but the quantity effect is not decisive. In particular, imagine a situation where $E$ has initially chosen an inefficiently small establishment size $N^{*}<N^{F B}$ due to the dominance of the quantity effect over the discouragement effect (see Corollary 1). If, at this moment, the economic situation of the establishment improves (i.e., $\theta$ increases), the employer may adjust the establishment size toward a more efficient level.

\section{Optimal Establishment Size under a Works Coun- cil}

After installing a works council, workers are able to formulate and submit collective demands to the employer (e.g., a new cafeteria or additional parking lots). Moreover, they can coordinate their interests by delegating the rent-seeking activities to the works council. The council then acts as a single agent on behalf of the workforce in a two-player rent-seeking contest against $E .^{16}$ In Subsection 5.1 , we consider the case of perfect worker coordination under a works council for the reason that the members of the works council are either perfectly loyal toward their co-workers or can be perfectly controlled by the workforce. This rather strong

\footnotetext{
${ }^{16}$ For the importance of a works council as a workforce's collective rent-seeking instrument, see Freeman and Lazear (1995) for theoretical and Frick and Möller (2003) for empirical considerations.
} 
assumption is skipped in Subsection 5.2, where we assume that there is an agency problem between the works council and the rest of the workforce. In such a setting, worker coordination is imperfect, and the workforce has to create incentives for the works council to spend effort and time in the rent-seeking contest. Subsection 5.3 addresses the special situation of mandated works councils in Germany.

\subsection{Perfect Coordination under a Works Council}

In this subsection, we abstract from possible agency problems between the works council and the rest of the workforce. Technically, this means that the $N$ workers collectively decide on the total rent-seeking expenditures $a_{W}$ that are to be invested by the works council in the two-player contest against $E$ for the distribution of discretionary profit $(1-\alpha) \pi(N)$. These expenditures $a_{W}$ are equally borne by the $N$ workers. Again, we solve the game by backwards induction. At the rent-seeking stage, worker $i$ 's objective function can be written as

$$
u_{W i}\left(a_{W}\right)=\frac{(1-\alpha) \pi(N)}{N} \frac{f\left(a_{W}\right)}{f\left(a_{E}+\Delta_{E}\right)+f\left(a_{W}\right)}-\frac{a_{W}}{N}
$$

and that of employer $E$ as

$$
u_{E}\left(N, a_{E}\right)=\alpha \pi(N)+(1-\alpha) \pi(N) \frac{f\left(a_{E}+\Delta_{E}\right)}{f\left(a_{E}+\Delta_{E}\right)+f\left(a_{W}\right)}-a_{E}
$$

with $\Delta_{E}$ indicating the strength of employer $E$ relative to the authority of the works council in the two-player contest. Since, for ease of notation, we skipped the influence of individual talents on the works council's impact function and since installing a works council typically increases the power of the workforce, $\Delta_{E}<\Delta$ seems realistic. The two first-order conditions together yield

$$
\frac{(1-\alpha) \pi(N)}{\left[f\left(a_{E}+\Delta_{E}\right)+f\left(a_{W}\right)\right]^{2}}=\frac{1}{f^{\prime}\left(a_{E}+\Delta_{E}\right) f\left(a_{W}\right)}=\frac{1}{f\left(a_{E}+\Delta_{E}\right) f^{\prime}\left(a_{W}\right)} .
$$

From the last equality we obtain $f\left(a_{E}+\Delta_{E}\right) / f^{\prime}\left(a_{E}+\Delta_{E}\right)=f\left(a_{W}\right) / f^{\prime}\left(a_{W}\right)$ and, hence, $a_{E}+\Delta_{E}=a_{W}$. Therefore, optimal expenditures are

$$
a_{W}^{*}=A\left(\frac{(1-\alpha) \pi(N)}{4}\right) \quad \text { and } \quad a_{E}^{*}=A\left(\frac{(1-\alpha) \pi(N)}{4}\right)-\Delta_{E} .
$$


At the second stage of the game, $E$ decides on establishment size. Under a works council with perfect worker coordination, $E$ chooses $N^{*}$ in order to maximize

$$
u_{E}\left(N, a_{E}^{*}\right)=\alpha \pi(N)+\frac{(1-\alpha) \pi(N)}{2}-A\left(\frac{(1-\alpha) \pi(N)}{4}\right)+\Delta_{E}
$$

We obtain the following result: ${ }^{17}$

Proposition 3 Under a works council, E implements $N^{F B}$.

This proposition highlights that the introduction of a works council, which serves purely as a rent-seeking device of the workforce, leads to efficient establishment size. The intuition is the following: without a works council, the employer chooses the optimal $N$ that trades off production against rent-seeking issues. Under a works council, however, this trade-off disappears since workers coordinate their actions, and $E$ can no longer influence the workforce's rent-seeking behavior by varying $N$. Accordingly, the employer's sole concern is for production, so that he chooses the efficient establishment size $N^{F B}$.

Having solved the complete game under a works council, we can now compare the employer's rent-seeking expenditures with and without a works council for optimally chosen establishment sizes. We have to contrast $a_{E}^{*}$ according to (10) for $N=N^{F B}$ with $a^{*}-\Delta$ from Section 4. Since $\frac{1}{4}>\frac{N^{*}}{\left(1+N^{*}\right)^{2}}$ (with $N^{*}$ denoting optimal establishment size without a works council) and $\pi\left(N^{F B}\right)>\pi\left(N^{*}\right)$, we immediately obtain the following result:

Proposition 4 If $\Delta_{E} \leq \Delta$, the employer will invest more in rent seeking under a works council.

In case of $\Delta_{E}<\Delta$, the employer chooses higher rent-seeking expenditures under a works council for three reasons: First, the reduction from $N+1$ to 2 contestants leads to more aggressive behavior of each player in the contest (i.e., the discouragement effect is reversed). Second, implementation of the efficient establishment size maximizes the rent $(1-\alpha) \pi(N)$ and, therefore, players' incentives

\footnotetext{
${ }^{17} \mathrm{As}$ in Section 4, again we concentrate on the case of interior solutions. For example, within the class of power impact functions (2) only interior solutions exist.
} 
in the contest. Third and last, $E$ invests the additional amount $\Delta-\Delta_{E}$ in rent seeking to compensate for the loss in relative strength.

According to Proposition 3, E benefits from a works council because it disentangles production and rent-seeking issues so that the employer chooses the efficient establishment size. However, Proposition 4 points out that a works council is also detrimental to $E$ as it increases his waste of resources in the rent-seeking contest. As in Section 4, let $N^{*}$ denote optimal establishment size without a works council. Comparing E's objective functions with and without a works council in equilibrium then leads to the following result:

Proposition 5 Let $\Delta=\Delta_{E}$. The employer will benefit from a works council if and only if

$$
\begin{aligned}
& \alpha\left[\pi\left(N^{F B}\right)-\pi\left(N^{*}\right)\right]+(1-\alpha)\left[\frac{\pi\left(N^{F B}\right)}{2}-\frac{\pi\left(N^{*}\right)}{1+N^{*}}\right] \\
& >A\left(\frac{(1-\alpha) \pi\left(N^{F B}\right)}{4}\right)-A\left(\frac{N^{*}(1-\alpha) \pi\left(N^{*}\right)}{\left(1+N^{*}\right)^{2}}\right) .
\end{aligned}
$$

Both sides of the inequality are strictly positive for $\alpha \in(0,1)$ since $\pi\left(N^{F B}\right)>$ $\pi\left(N^{*}\right)$ and $\frac{1}{2}>\frac{1}{1+N}$ as well as $\frac{1}{4}>\frac{N}{(1+N)^{2}}$. The right-hand side measures $E^{\prime}$ 's disadvantage from a works council in the form of higher expenditures arising from a more aggressive behavior in the rent-seeking contest, which is reinforced by a larger rent $(1-\alpha) \pi\left(N^{F B}\right)>(1-\alpha) \pi\left(N^{*}\right)$. The left-hand side describes $E$ 's efficiency gains from a works council, inducing the first-best establishment size. Moreover, the left-hand side shows that when there is a works council, the employer also obtains a larger share in the rent $(1-\alpha) \pi(N)$ since $\frac{1}{2}>\frac{1}{1+N}$. Note that the welfare effects of a works council are not clear. As pointed out above, welfare increases due to the implementation of the efficient scale of production. However, concerning rent seeking a works council is only welfare improving if the increased waste of resources of $E$ is outweighed by a reduced number of rent seekers. 


\subsection{Imperfect Coordination under a Works Council}

In this subsection, we skip the assumption of perfect worker coordination. Instead, we assume that there is an agency problem between the $n<N$ members of the works council and their $N-n$ co-workers. ${ }^{18}$ The incentive problem arises from the fact that council members have to bear personal costs when investing in rent seeking and that their efforts cannot be perfectly controlled by the $N-n$ other workers. However, the $N-n$ non-council members can set up an incentive scheme in order to influence the council members' behavior.

We assume that the $n$ members collectively decide on the works council's investment in the rent-seeking contest, which is again denoted by $a_{W}$. The corresponding costs $a_{W}$ are equally borne by all council members. The $N-n$ noncouncil members cannot directly determine $a_{W}$, but they can create incentives for the council members by offering them a share $\gamma \in(0,1)$ in the acquired rent $(1-\alpha) \pi(N) f\left(a_{W}\right) /\left[f\left(a_{E}+\Delta_{E}\right)+f\left(a_{W}\right)\right]$. The remaining share $1-\gamma$ accrues to the $N-n$ non-council members. Hence, each council member realizes utility

$$
u_{c}\left(a_{W}\right)=\frac{\gamma(1-\alpha) \pi(N)}{n} \frac{f\left(a_{W}\right)}{f\left(a_{E}+\Delta_{E}\right)+f\left(a_{W}\right)}-\frac{a_{W}}{n}
$$

whereas each non-council member gets utility

$$
u_{n c}\left(a_{W}\right)=\frac{(1-\gamma)(1-\alpha) \pi(N)}{N-n} \frac{f\left(a_{W}\right)}{f\left(a_{E}+\Delta_{E}\right)+f\left(a_{W}\right)} .
$$

Share $\gamma$ is chosen such that workers' total income $n \cdot u_{c}\left(a_{W}\right)+(N-n) \cdot u_{n c}\left(a_{W}\right)$ is maximized. For analytical tractability, we assume that the impact function $f$ belongs to the family of power functions, being described by (2). The timing of the game is identical to the one in Subsection 5.1 with the exception that prior to the contest the workers fix share $\gamma$ that satisfies $\max _{\gamma}\left(n \cdot u_{c}\left(a_{W}\right)+(N-n) \cdot u_{n c}\left(a_{W}\right)\right)$ and that during the contest the $n$ council members together choose $a_{W}$ to maximize $u_{c}$.

The game is solved by backward induction, beginning with the simultaneous choices of $a_{W}$ and $a_{E}$ in the contest for a given share $\gamma$ and given establishment

\footnotetext{
${ }^{18}$ We do not discuss how the members of the works council are selected. For example, we can assume that each worker becomes a member with probability $n / N$.
} 
size $N$. Whereas the council members maximize $u_{c}$, the employer chooses $a_{E}$ in order to maximize (8). Using (2), the first-order conditions can be summarized to

$$
\frac{\beta(1-\alpha) \pi(N)}{\left[\left(a_{E}+\Delta_{E}\right)^{\beta}+a_{W}^{\beta}\right]^{2}}=\frac{1}{\gamma\left(a_{E}+\Delta_{E}\right)^{\beta} a_{W}^{\beta-1}}=\frac{1}{\left(a_{E}+\Delta_{E}\right)^{\beta-1} a_{W}^{\beta}}
$$

Solving for the optimal rent-seeking expenditures $a_{E}^{*}$ and $a_{W}^{*}$ yields $\gamma\left(a_{E}^{*}+\Delta_{E}\right)=$ $a_{W}^{*}$ and, finally,

$$
a_{E}^{*}=\frac{\beta \gamma^{\beta}(1-\alpha) \pi(N)}{\left(1+\gamma^{\beta}\right)^{2}}-\Delta_{E} \quad \text { and } \quad a_{W}^{*}=\frac{\beta \gamma^{\beta+1}(1-\alpha) \pi(N)}{\left(1+\gamma^{\beta}\right)^{2}}
$$

Prior to the contest, the workers choose

$$
\begin{aligned}
\gamma^{*} & =\arg \max _{\gamma}\left(n \cdot u_{c}\left(a_{W}^{*}\right)+(N-n) \cdot u_{n c}\left(a_{W}^{*}\right)\right) \\
& =\arg \max _{\gamma}\left((1-\alpha) \pi(N) \frac{\gamma^{\beta}\left(\gamma^{\beta}-\beta \gamma+1\right)}{\left(\gamma^{\beta}+1\right)^{2}}\right) .
\end{aligned}
$$

Assuming that the workers' objective function is strictly concave, ${ }^{19} \gamma^{*}$ is described by the first-order condition, which can be rewritten to

$$
(1+\beta) \gamma^{*}+(1-\beta) \gamma^{* \beta+1}-\left(1+\gamma^{* \beta}\right)=0
$$

Implicit differentiation shows that $\partial \gamma^{*} / \partial \beta>0$. Hence, optimal incentives increase in the power parameter, which is also intuitively plausible: the greater the marginal impact of an effort increase, the higher should be the optimal incentives set by the workers for the works council.

At the beginning of the game, the employer chooses optimal establishment size. He maximizes (8), anticipating that the workers will set incentives $\gamma^{*}$ and that equilibrium expenditures in the contest will be $a_{E}^{*}$ and $a_{W}^{*}$. Inserting into (8) leads to

$$
u_{E}\left(N ; \gamma^{*}\right)=\left(\alpha+(1-\alpha) \frac{1+(1-\beta) \gamma^{* \beta}}{\left(\gamma^{* \beta}+1\right)^{2}}\right) \pi(N)+\Delta_{E}
$$

as E's objective function. The first-order condition immediately yields $\pi^{\prime}(N)=$

\footnotetext{
${ }^{19}$ For given values of $\beta$ (e.g., $\beta=1$ or $\beta=0.5$ ), it can be easily checked that this is indeed the case.
} 
0. Hence, the employer prefers to choose the efficient establishment size $N^{F B}$. The intuition is the same as under perfect worker coordination: introduction of a works council disentangles production and rent-seeking issues when fixing optimal establishment size. As a consequence, the discouragement effect and the quantity effect are eliminated and $E$ pays attention exclusively to efficient production.

Comparing the outcome without a works council to that under a works council with imperfect worker coordination gives the following result:

Proposition 6 Under imperfect worker coordination, E implements $N^{F B}$. Let $\Delta_{E} \leq \Delta$; if $\gamma^{*}$ is sufficiently large, employer $E$ will invest more in rent seeking under a works council than without a works council. If $\Delta_{E}=\Delta$, the employer strictly benefits from a works council.

As under perfect worker coordination, $E$ fixes establishment size at the efficient level because the introduction of a works council deletes both the discouragement and the quantity effect. It is not clear, though, whether $E$ spends more resources under a works council than without one. Again, a higher rent and a reduction in the number of contestants boost the competition in the contest, and $E$ wants to compensate for the lost relative authority $\Delta-\Delta_{E}$. However, if the players' marginal impact in the contest is very low so that it does not pay for the workers to induce high incentives $\gamma^{*}$, the waste of resources in the rent-seeking contest will be rather low. If this effect dominates the three other effects, $E$ will invest less resources under a works council with imperfect worker coordination than without a council. Restored production efficiency, the induced distribution of the rent between employer and workforce, and the induced resource expenditures together make $E$ prefer the introduction of a works council with imperfect coordination.

\subsection{The Case of German Works Councils}

In Germany, the Works Constitution Act allows workers to establish a works council, if the number of workers exceeds a threshold of four regular workers. Since the employer cannot veto the establishment of a works council, we speak of a mandatory works council. The Works Constitution Act assures the workforce a particular bundle of codetermination rights. This bundle further increases when 
the establishment size exceeds certain thresholds. Moreover, the employer has to bear the full costs of setting up and running a works council, and these costs rise in establishment size. For example, the employer has to pay a number of full-time council members, and their number increases in establishment size. ${ }^{20}$

We could supplement our model by adding two characteristics specific to German works councils. A bundle of codetermination rights that increases in establishment size could be modeled via replacing $\Delta_{E}$ by $\Delta_{E}(N)$ with $\Delta_{E}^{\prime}(N)<0$ (i.e., $E$ 's relative strength decreases in the number of employed workers). In addition, we could introduce a new cost function $\kappa(N)>0$ with $\kappa^{\prime}(N)>0$ that denotes E's operational costs from running a works council. $\kappa(N)$ is subtracted from the employer's utility $u_{E}$.

Irrespective of whether we add $\Delta_{E}(N)$ and $\kappa(N)$ to the works council model with perfect or imperfect worker coordination, the consequence for $E$ 's optimal choice of establishment size is qualitatively the same: both functions penalize firm growth and, thus, induce the employer to adjust the efficient establishment size downwards. Several empirical papers have analyzed the impact of the German Employment Protection Act and the Works Constitution Act on the growth of German workforces. ${ }^{21}$ Both laws have led to an increase in employment rights and to additional costs for the employer where the establishment size exceeds certain thresholds. However, none of the papers finds that the legal thresholds prescribed in the two laws have retarded firm growth in Germany.

In each of the two scenarios, with and without a works council, the unions also play an important role in workers' wages in Germany. Typically one union collectively bargains with the corresponding employers' association for industrywide wages and working conditions. The collective agreement defines the minimum requirements for all workers - irrespective of their being members of a union or not - employed by firms which belong to a certain sector and region (e.g., the metal working industry in North Rhine-Westphalia). Works councils, which are installed at establishment level, also have a say in workers' wages. The situation in

\footnotetext{
${ }^{20}$ See Addison et al. (2000, p. 16) and Addison et al. (2001, pp. 663-665) on the council's authority and the employer's operational costs for a council, which both increase in establishment size.

${ }^{21}$ See Wagner et al. (2001), Verick (2004), Burgert (2006), Koller et al. (2008), and Koller (2010).
} 
Germany is characterized by vaguely defined jobs and exactly defined pay-grades, that is, by a rough description of tasks performed at a certain job, on the one hand, and precisely calculated wages, on the other. The rough characterization of jobs entails bargaining at establishment level about which jobs should be assigned to which pay-grades. More intense rent-seeking in a particular establishment either by individual workers or by a works council, as a collective representative of the whole workforce - leads to more jobs and, hence, to more workers benefiting from higher pay-grades within that establishment. If workers act as individual rent-seekers, an upgrading of some workers often leads to a downgrading of others. However, a works council tends to redistribute income from the employer to the workforce as a whole. These characteristics fit quite well with our set-up, where a works council leads to worker coordination. In our econometric analysis, based on German data, we control for the influence of collective wage bargaining via unions at industry and firm levels.

\section{Empirical Evidence}

This section offers an empirical analysis of the main theoretical statements, the aim being twofold. (1) Without a works council, there are two countervailing effects which influence the rent seeking of workers - the discouragement and the quantity effect. Hence, we seek empirical evidence on which of the two effects is more relevant in practice. (2) According to theory, the introduction of a works council erases both the discouragement and the quantity effect, under either degree of worker coordination. Intuitively, the works council substitutes the $N$ individual workers as rent seekers. What remains is the influence of establishment size on profit, but this is also the case where there is no works council. We therefore expect that in establishments with a works council the number of workers no longer has a significant influence on the degree of rent seeking. At least, we assume that works councils mitigate the quantity or discouragement effect, respectively.

For our investigation we use the data of the Establishment Panel of the German Institute for Employment Research (IAB). This establishment-level survey contains information about the establishments' business policies and developments, 
innovations, workforce structures, recruitment and separation decisions, wages, working times, apprenticeship, and further training programs, industrial relations, etc. Meanwhile, the Establishment Panel provides yearly information about more than 16,000 establishments of all establishment sizes and industries, which makes it the most extensive establishment-level data set in Germany. In our empirical investigation we make use of the recent panel waves of the years 2001 to $2008 .^{22}$

\subsection{Econometric Model}

In order to investigate the importance of the quantity and the discouragement effect empirically, our econometric model must reflect the internal contest for the contractually not guaranteed part of establishment profit, $(1-\alpha) \pi(N)$. Specifically, we need an empirical measure that illustrates the distribution of this part between employer and workers. A natural candidate to meet this requirement is an establishment's wage bill-to-total sales ratio $W / Y$. This holds for several reasons. First, $W / Y$ can be interpreted in terms of establishment profitability because it captures the amount of establishment productivity earned by the workers. $W / Y$ thus illustrates inverse establishment profitability in relative terms. Second, $0 \leq W / Y \leq 1$ so that $W / Y$ can be interpreted as a share. Third, to some extent $W / Y$ reflects the workers' share in $(1-\alpha) \pi(N)$, i.e., $\sum_{i=1}^{N} s_{i}\left(a_{i}\right)$, where $s_{i}\left(a_{i}\right)$ is defined in equation (3). Finally, larger values of $W / Y$ indicate an increasing share of establishment output being transferred to the $N$ workers at the expense of employer $E$, which illustrates the redistribution issue that is associated with rent-seeking contests. In particular, as mentioned in Subsection 5.3, rent seeking in German establishments can influence the assignment of jobs to pay-grades. More intense rent seeking is therefore likely to yield an upgrading of jobs, thus

\footnotetext{
${ }^{22}$ Our analysis is restricted to establishments that employ at least five workers. The reason for this restriction is that, according to the German Works Constitution Act, employees are only allowed to elect a works council when the total workforce of the establishment exceeds the number of four employees. We also exclude agricultural and forestry establishments, non-profit establishments, and the public sector. Furthermore, we exclude establishments of the banking and insurance sector because our dependent variable (wage bill-to-sales ratio) is based on total sales. However, since the corresponding measure for banks and insurance companies is based on total assets instead of total sales, we decided not to consider them in our analysis. Finally, we adjusted our sample by eliminating obvious outliers, e.g., regarding establishment size and the wage bill-to-total sales ratio.
} 
increasing the total wage bill relative to sales. All in all, therefore, our empirical measure comes quite close to the corresponding theoretical measure, which is why we use $S=W / Y$ as the dependent variable in our empirical model. ${ }^{23}$

Both the quantity and the discouragement effect directly relate the amount of rent-seeking activities to establishment size. Hence, our first explanatory variable of interest is establishment size, which is measured by the number of workers, $N$. Regressing $S$ on $N$ provides us with information as to whether the quantity effect or the discouragement effect is actually valid. Our second variable of interest, $C$, is a dummy variable indicating whether or not an establishment has a works council. According to the implications of our theoretical model, a works council may reinforce or mitigate rent-seeking activities. A reinforcing effect is likely to occur if we observe the discouragement effect, while a mitigating effect can be expected under the conditions of the quantity effect.

In our baseline specification, we separate establishments under a works council $(C=1)$ from establishments without a works council $(C=0)$. The corresponding estimation equations can be written as

$$
\begin{aligned}
& S_{0 i t}=\alpha_{0} N_{i t}+X_{i t} \beta_{0}+\mu_{0 i}+\xi_{0 t}+u_{0 i t} \\
& S_{1 i t}=\alpha_{1} N_{i t}+X_{i t} \beta_{1}+\mu_{1 i}+\xi_{1 t}+u_{1 i t} .
\end{aligned}
$$

Equation (12) represents the regime of establishments without a works council, while equation (13) represents establishments under a works council. $X$ is a matrix of control variables. The subscripts $i$ and $t$ indicate establishment and time, respectively. $\alpha_{0}, \alpha_{1}, \beta_{0}$, and $\beta_{1}$ are the parameters to be estimated, where we are particularly interested in $\alpha_{0}$ and $\alpha_{1}$. Potential macroeconomic shocks are specified by $\xi_{0 t}$ and $\xi_{1 t}$ and will be captured by a series of time dummies. Regarding the error terms, we apply the usual white noise assumptions, i.e., $u_{0} \sim N\left(0, \sigma_{0}^{2}\right)$ and

\footnotetext{
${ }^{23}$ To the best of our knowledge, using the wages-to-total sales ratio as a rent-seeking measure is quite unique. However, according to the related literature it is not unusual to apply profitability measures as an indicator of rent seeking. For example, Kraft and Lang (2008) and Jirjahn (2009) use the subjective evaluations made by establishment representatives of establishment profitability to construct a rent-seeking indicator. Furthermore, Beckmann et al. (2010) use value added, value added per capita, value added minus wages, and value added minus wages per capita as alternative rent-seeking measures. As a final point, the idea to examine rentseeking behavior in a regression model, where the dependent variable indicates firm profitability, has already been applied in Hirsch (1990).
} 
$u_{1} \sim N\left(0, \sigma_{1}^{2}\right)$. Finally, $\mu_{0 i}$ and $\mu_{1 i}$ reflect unobserved time-invariant establishment characteristics (e.g., management quality). If these establishment-specific effects were correlated with both the explanatory and dependent variables in (12) and (13), the parameter estimates would be biased and inconsistent, unless the estimation approach explicitly controls for unobserved heterogeneity. In order to eliminate potential biases caused by unobserved fixed effects, we exploit the panel structure of our data and apply the within estimator.

However, apart from unobserved establishment characteristics the parameter estimates may be affected by another endogeneity problem, i.e., selectivity. The selectivity problem may arise because establishments are not randomly assigned to a certain works council regime. Potential selection biases in the parameter estimates can be avoided by specifying an endogenous switching regression model (Maddala 1983):

$$
\begin{aligned}
& S_{0 i t}=\alpha_{0} N_{i t}+X_{i t} \beta_{0}+\mu_{0 i}+\xi_{0 t}+u_{0 i t} \\
& S_{1 i t}=\alpha_{1} N_{i t}+X_{i t} \beta_{1}+\mu_{1 i}+\xi_{1 t}+u_{1 i t} \\
& C_{i t}^{*}=\delta N_{i t}+Z_{i t} \gamma+\nu_{i}+\zeta_{t}+\varepsilon_{i t} .
\end{aligned}
$$

Equation (16) explicitly addresses the selectivity problem in terms of works council status by modeling the determination of the workers' propensity to elect a works council $C^{*}$. Theoretically, $C^{*}$ depends on the profitability differences between establishments with and without a works council and the costs associated with the existence of a works council. Empirically, the relative benefit of an existing works council is captured by a set of establishment characteristics given by $N$ and $Z$, where $Z=[X I]$ and $I$ contains identifying instrumental variables not included in equations (14) and (15). $\nu_{i}$ and $\zeta_{t}$ in (16) correspond to $\mu_{j i}$ and $\xi_{j t},(j=0,1)$ in the regime equations.

Since $C^{*}$ is a latent variable and thus unobserved, we replace $C^{*}$ in equation (16) with a dummy variable that takes the value 1 if the establishment has a works 
council and 0 if it does not, i.e.,

$$
C_{i t}= \begin{cases}1 & \text { if } C_{i t}^{*}>0 \\ 0 & \text { if } C_{i t}^{*} \leq 0\end{cases}
$$

In order to account for both selectivity and unobserved establishment characteristics simultaneously, we augment our endogenous switching regression model, applying an approach suggested by Mundlak (1978). That means we parameterize the establishment-specific effects as a linear function of the within establishment means of all (time varying) explanatory variables, ${ }^{24}$ i.e.,

$$
\mu_{j i}=\tilde{\alpha}_{j} \bar{N}_{i}+\bar{X}_{i} \tilde{\beta}_{j}+\omega_{j i} \quad ; \quad j=0,1
$$

and

$$
\nu_{i}=\tilde{\delta} \bar{N}_{i}+\bar{Z}_{i} \tilde{\gamma}+\eta_{i}
$$

Here, $\bar{N}_{i}=1 / T_{i} \sum_{t} N_{i t}, \bar{X}_{i}=1 / T_{i} \sum_{t} X_{i t}$, and $\bar{Z}_{i}=1 / T_{i} \sum_{t} Z_{i t}$ with $T_{i}$ being the span of years an establishment can be observed in the panel data set. The unobserved effects $\omega_{j i}$ and $\eta_{i}$ are assumed to be uncorrelated with the original regressors $N, X$ and $Z$, respectively, where $\omega_{j i} \sim N\left(0, \sigma_{\omega_{j}}^{2}\right)$ and $\eta_{i} \sim N\left(0, \sigma_{\eta}^{2}\right)$.

By adding expressions (18) and (19) to the regime equations (14) and (15) and the selection equation (16), our econometric model, which simultaneously accounts for unobserved heterogeneity and selectivity, takes the following form:

$$
\begin{aligned}
S_{0 i t} & =\alpha_{0} N_{i t}+X_{i t} \beta_{0}+\xi_{0 t}+\tilde{\alpha}_{0} \bar{N}_{i}+\bar{X}_{i} \tilde{\beta}_{0}+\omega_{0 i}+u_{0 i t} \\
S_{1 i t} & =\alpha_{1} N_{i t}+X_{i t} \beta_{1}+\xi_{1 t}+\tilde{\alpha}_{1} \bar{N}_{i}+\bar{X}_{i} \tilde{\beta}_{1}+\omega_{1 i}+u_{1 i t} \\
C_{i t} & =\delta N_{i t}+Z_{i t} \gamma+\zeta_{t}+\tilde{\delta} \bar{N}_{i}+\bar{Z}_{i} \tilde{\gamma}+\eta_{i}+\varepsilon_{i t} .
\end{aligned}
$$

\footnotetext{
${ }^{24}$ Our procedure is similar to the estimation strategy applied in Dustmann and Schmidt (2000), who investigate the wage effects of immigrant women working full-time, part-time, or not at all. The authors also combine an endogenous switching regression model with the Mundlak approach. Moreover, Beatty et al. (2010) estimate an endogenous switching regression model using withinestablishment means in the selection and the regime equations to exploit the panel structure of their data. Finally, the Mundlak approach or the related Chamberlain-Mundlak approach, controlling for correlated fixed effects, has recently been used, e.g., in Jones et al. (2007), Abdulai and Tietje (2007), and Fitzenberger et al. (2011).
} 
For the composite error terms in equations (20), (21), and (22), i.e., $\omega_{j i}+u_{j i t}=\tilde{u}_{j i t}$ $(j=0,1)$ and $\eta_{i}+\varepsilon_{i t}=\tilde{\varepsilon}_{i t}$, we assume a jointly trivariate normal distribution, where the variances are given by $\sigma_{\tilde{u}_{j t}}^{2}$ and $\sigma_{\tilde{\varepsilon}}^{2}=1$. The covariances between the composite error terms of the regime equations $\tilde{u}_{j i t}$ and the selection equation $\tilde{\varepsilon}_{i t}$ are defined as $\sigma_{\left(\tilde{\varepsilon}, \tilde{u}_{j}\right) t}$ so that the corresponding correlation coefficients are obtained by $\rho_{\left(\tilde{\varepsilon}, \tilde{u}_{j}\right) t}=\sigma_{\left(\tilde{\varepsilon}, \tilde{u}_{j}\right) t} / \sigma_{\tilde{u}_{j t}}$ (Dustmann and Schmidt 2000, p. 7).

The equation system (20), (21), and (22) is estimated simultaneously using the full information maximum likelihood method (Lokshin and Sajaia 2004). Remember that we are particularly interested in the estimates of $\alpha_{0}$ and $\alpha_{1}$. For example, $\alpha_{0}>0$ and $\alpha_{0}>\alpha_{1} \geq 0$ would provide some evidence for the quantity effect being present in establishments without a works council, whereas works councils tend to mitigate the workers' rent-seeking activities. On the other hand, $\alpha_{0}<0$ and $\alpha_{0}<\alpha_{1} \leq 0$ would indicate a presence of the discouragement effect in establishments without a works council, whereas works councils engage in rent seeking, at least to some extent, thereby counteracting the discouragement effect.

Note that our data capture the observation period between the years 2001 and 2008. Within this time span, there are only a few establishments that have switched from the non-works council to the works council regime or vice versa. All in all, we identified less than $5 \%$ of the establishments as status switchers. From the methodological viewpoint, however, the existence of status switchers is associated with the rather confusing fact that one particular establishment might belong to different regimes (20) and (21) at different times. Intuitively, we think of works council status as a (quasi) time-invariant variable, at least over a relative short observation period of eight years. In order to ensure that a particular establishment either belongs to the works council regime or the non-works council regime over the entire observation period, we exclude the 'status switchers' from our model. This means we are interested in the question of whether the estimation results are substantially influenced by the status switchers. In this variant of our endogenous switching regression model, the selection equation (22) thus changes to

$$
C_{i}=\tilde{\delta} \bar{N}_{i}+\bar{Z}_{i} \tilde{\gamma}+\tilde{\eta}_{i}
$$

All in all, therefore, we provide estimation results for the equation system (20), 
(21), and (22) as well as for its variant (20), (21), and (23).

\subsection{Estimation Results}

In order to be able to interpret the parameters $\alpha_{0}$ and $\alpha_{1}$ in the sense of the quantity or the discouragement effect, respectively, our econometric model must consider alternative explanations for inverse establishment profitability $S$ beyond the assumed rent-seeking effects. These alternative explanations are captured by the control variables matrix $X$. For example, establishment profitability may be affected by technological investments or the internal diffusion of technological innovations. Similarly, establishments with a large share of skilled and high-skilled workers are also likely to differ from establishments employing mostly unskilled workers in terms of profitability. Consequently, our regressor matrix $X$ includes two measures on technological innovations (technical state of technologies in use, expansion investments per capita) as well as the share of skilled workers (and other variables providing information on the structure of the workforce). Finally, $S$ might also be driven by collective wage bargaining arrangements as well as extra payments above the level of negotiated wages. These extra payments might be paid in order to increase the workers' effort or retain the most productive employees. Our regressor matrix therefore contains the corresponding dummy variables for union representation ${ }^{25}$ and the existence of extra payments that go beyond the collectively bargained wage level. Hence, by explicitly addressing these alternative explanations, the control variables in $X$ contribute to improving the accuracy of $\alpha_{0}$ and $\alpha_{1}$ being interpreted as rent-seeking effects.

Regarding the remaining control variables, we consider measures that are quite standard in the literature on performance effects of works councils or other forms of employee participation (e.g., Addison et al. 2001, Addison et al. 2006, Zwick 2004, Kraft and Lang 2008). For example, the influence of an establishment's activities abroad is captured by the export share. Finally, $X$ contains measures on sector

\footnotetext{
${ }^{25}$ Alternatively, we ran both the fixed effects models as well as the endogenous switching regression models replacing the collective wage bargaining variable by two dummy variables capturing establishment-level and sectoral-level collective bargaining, respectively. However, we did not achieve additional insights from splitting the collective bargaining dummy into two parts, so we decided not to change our original specification.
} 
and regional affiliation as well as other relevant establishment characteristics. ${ }^{26}$

As the discussion in the previous subsection makes clear, works council status is likely to be endogenous. In order to avoid a parameter identification that relies solely on functional form assumptions, the $Z(\bar{Z})$ matrix in selection equations (22) and (23), respectively must contain one or more exclusion restrictions, i.e., identifying variables that are not included in $X(\bar{X}) .{ }^{27}$ To be a valid instrument, an exclusion restriction must be relevant (i.e., it must be correlated with works council status) and exogenous (i.e., it should not be correlated with the error terms in the regime equations).

In the present case, we apply two exclusion restrictions to instrument works council status. First, we use a measure of establishment age, expecting that older establishments are more likely to have a works council than younger ones. ${ }^{28}$ This assumption can be explained by a simple time effect. In older establishments workers have already had more opportunities to elect a works council than their colleagues in younger establishments. In order to capture this age effect, we generate a dummy variable that indicates whether or not an establishment has been founded later than 1990. If our expectations were true, this dummy variable should be negatively correlated with works council incidence. Moreover, regarding the exogeneity requirement there is no reason to assume that establishment age has a direct influence on establishment performance (i.e., wage bill-to-total sales ratio in the present case).

Our second exclusion restriction is a dummy variable indicating whether or not an establishment expects a reduction in total employment. ${ }^{29}$ We assume that negative employment expectations are more likely to prevail in works council es-

\footnotetext{
${ }^{26} \mathrm{~A}$ description of all variables applied in the empirical investigation can be found in Table 3 in the appendix.

${ }^{27}$ On the other hand, note that identification of the parameters of an endogeneous switching regression model does not necessarily require the $Z(\bar{Z})$ matrix to contain each of the $X(\bar{X})$ variables.

${ }^{28}$ Empirical evidence confirming this hypothesis can be found, e.g., in Addison et al. (1997). Fister (2002) proceeds similarly to our identification strategy using company age as an instrument for unionization instead of works council incidence.

${ }^{29}$ For example, Kraft and Lang (2008) and Jirjahn (2009) also use variables on employment changes as potential determinants of works council adoption. While Jirjahn (2009) examines the impact of employment growth on works council introduction, Kraft and Lang (2008) specify two dummy variables capturing future employment expectations and estimate their influence on works council introduction.
} 
tablishments. Our argument is based on the insider-outsider approach of Lindbeck and Snower $(1987,1988)$. According to this approach, a works council is primarily interested in protecting the insiders against the employer and potentially new employees (outsiders). In particular, the works council wants to shift rents from the employer to the insiders and to inhibit the hiring of outsiders, who would otherwise participate in the insider rents. As a consequence, the employer expects a non-increasing establishment size and, in times of crisis, a decreasing one. Hence, we assume that establishments with negative employment expectations are more likely to have a works council. On the other hand, there is no reason to believe that an establishment's expectation regarding employment growth has a direct impact on its current profitability.

Corresponding to our methodological approach, i.e., addressing unobserved establishment characteristics and selectivity issues simultaneously, we use the within means of both the establishment age dummy and the employment expectations dummy in each of the selection equations (22) and (23). ${ }^{30}$ Note that since we desist from additionally applying the establishments' periodical values of our exclusion restrictions, $Z_{i t}$ in $(22)$ alters to $X_{i t}$.

The estimates for our main explanatory variable $N$ resulting from our baseline fixed effects models (12) and (13) as well as the equation systems (20), (21), (22) and (20), (21), (23) are displayed in Table $1 .^{31}$

\section{[Insert Table 1 about here]}

The most striking result is that establishment size has a significantly negative effect on the wage bill-to-total sales ratio in establishments without a works council $\left(\alpha_{0}<0\right)$. This holds in all of our specifications irrespective of whether or not we account for the endogeneity of works council status. However, the estimates

\footnotetext{
${ }^{30}$ Contrary to a first conjecture the establishment age dummy is not time-constant. About $7.5 \%$ of the establishments in our sample exhibit at least one change in the establishment age dummy over time. This time-variation can be explained by organizational changes within establishments. For example, establishments may have executed insourcing or outsourcing activities within the considered time-span. Another explanation is a change with regard to ownership. These organizational changes might be interpreted as quasi new foundations.

${ }^{31}$ The estimates for the control variables and the selection equation of model (20), (21), and (22) can be found in Table 4 in the appendix. The corresponding estimates of equation system (20), (21), (23) are available from the authors upon request.
} 
of the correlation coefficients $\rho_{\tilde{\varepsilon}, 0}=\rho_{\tilde{\varepsilon}, \tilde{u}_{0}}$ and $\rho_{\tilde{\varepsilon}, 1}=\rho_{\tilde{\varepsilon}, \tilde{u}_{1}}$ as well as the Wald test on independence of the selection and regime equations clearly demonstrate the requirement of accounting for selectivity. Contrary to the non-works council regime, we find no significant establishment size effect on the wage bill-to-total sales ratio for establishments under a works council $\left(\alpha_{1}=0\right)$. A Wald test on $\alpha_{0}=\alpha_{1}$ shows that the establishment size effect significantly differs between the works council and the non-works council regime.

Furthermore, the positive estimates of $\rho_{\tilde{\varepsilon}, 0}$ and $\rho_{\tilde{\varepsilon}, 1}$ indicate that establishments self-selecting into a certain works council regime are more profitable than a random establishment from the sample would have been. ${ }^{32}$ In particular this holds for establishments in the non-works council regime $\left(\rho_{\tilde{\varepsilon}, 0}\right.$ is highly significant) and to a lesser extent for establishments choosing the works council regime $\left(\rho_{\tilde{\varepsilon}, 1}\right.$ is insignificant). Two tests confirm the validity of our exclusion restrictions. First, a $\chi^{2}$-test on joint significance of the exclusion restrictions strongly support the relevance of both instruments. Second, according to the $\chi^{2}$-test of overidentification we cannot reject the null hypothesis of exogenous instruments. ${ }^{33}$ Finally, the $\chi^{2}$-test on joint significance of the controls for correlated fixed effects clearly demonstrates the necessity of taking unobserved establishment characteristics into account.

All in all, we conclude from our results that there is no empirical evidence for the quantity effect. However, the results support the hypothesis of a discouragement effect to be observed in establishments without a works council. Hence, the wage bill-to-total sales ratio decreases (or, equivalently, relative profitability increases) with establishment size only in establishments without a works council but not those with a works council. This finding indicates that works councils aim at intensifying rent-seeking activities by acting against the discouragement effect.

\footnotetext{
${ }^{32}$ Note that a positive correlation coefficient implies that self-selection is associated with a lower wage bill-to-total sales ratio relative to random assignment.

${ }^{33}$ Since there is no standard test of overidentifying exclusion restrictions in the context of an endogeneous switching regression model, we alternatively perform the Sargan test known, e.g., from the two-stage least squares framework as well as the Hausman test, which is also applied in Lokshin and Beegle (2011). By means of an F-test we finally check whether our exclusion restrictions are jointly insignificant in the regime equations using the estimated regime residuals as dependent variables. Table 1 displays the statistics from the conventional Sargan test used for model (20), (21), (22) and a modified Sargan test used for model (20), (21), (23). The modified Sargan test takes into account that selection equation (23) does only include within means and no periodical values. The results of the Hausman test and the $F$-test are in line with the statistics reported.
} 
We conducted several sensitivity checks to test whether our fixed effects and endogenous switching regression model estimates are robust to alternative specifications. First, we considered the common observation that almost all of the very large establishments have a works council, so establishment size $N$ might be truncated at higher values in the non-works council regime. We therefore ran additional regressions using a restricted sample in which maximum establishment size is determined by the largest establishment without a works council. Proceeding that way, we secure that both the smallest and the largest establishments in the sample may or may not have a works council. Maximum establishment size in the restricted sample is $N=5,011$, while it is $N=19,671$ in the unrestricted sample. ${ }^{34}$ The estimation results of the restricted sample are very similar to the results presented. Most importantly, we can still observe a significant discouragement effect in the non-works council regime, but we find no significant establishment size effect in the works council regime. Second, we examined whether our results change, when we assume a non-linear establishment size effect on rent seeking. For this purpose, we specified both a semi-logarithmic model using $\ln N$ as our main explanatory variable and a quadratic version adding $N^{2}$ to the original specification. Again, the estimation results are consistent with the results presented in the paper. Third, we replaced our dependent variable, i.e., the wage bill-to-total sales ratio, by the wage bill-to-value added ratio and thus test, whether our results are affected by the choice of our rent-seeking measure. However, we obtain qualitatively very similar results with respect to magnitude and significance of the observed discouragement effect. $^{35}$ Finally, we checked whether our estimates depend on the choice of our exclusion restrictions. Precisely, we examined whether our findings alter, when we include only one of the exclusion restrictions (within mean of the establishment age or the employment expectations dummy) to the selection equations instead of both. We also experienced with a specification treating the periodical values as well as the within means of both dummy variables as exclusion restrictions in (22).

\footnotetext{
${ }^{34}$ Restricting the sample was associated with a reduction in the number of observations (establishments) by 100 (29) from 54,573 (18,229) to 54,473 (18,200).

${ }^{35}$ We prefer a specification containing the wage bill-to-total sales ratio rather than the wage bill-to-value added ratio in order to avoid a potential item non-response bias that might be associated with applying the value added variable.
} 
Again, we obtain estimates confirming our previous findings. ${ }^{36}$

\subsection{Complementing Model Specification}

Remember that in the previous empirical analysis we used an establishment's wage bill-to-total sales ratio $S_{i}=W_{i} / Y_{i}$ as a measure for rent seeking (conditional on the covariates). In the first instance, however, $S$ may be seen as providing information mainly on (inverse) profitability or cost effectiveness rather than rent seeking. The question is: How we can be convinced that interpreting $S$ in terms of rent seeking is appropriate? In order to check our interpretation of $S$ as a rent-seeking indicator, we specify an additional estimation model. If the results of this complementing model were consistent with our reasoning so far, the view of $S$ to be interpreted as a rent-seeking measure would gain additional support.

In our complementing specification, we regress our rent-seeking measure $S$ on a set of explanatory variables providing new information on the quality of cooperation between management and works council. More precisely, the level of cooperation with the works council is captured by three dummy variables. The first dummy variable captures establishments where the management faces a rather non-cooperative works council usually opposing management decisions $\left(C^{n c}\right)$. The second dummy variable captures establishments with a rather cooperative works council that typically agrees with management decisions $\left(C^{c}\right)$. The final dummy variable captures establishments with works councils whose behavior is somewhere in between cooperative and non-cooperative behavior. ${ }^{37}$

We expect the cooperative works councils to succeed in rent-seeking activities so that the impact of $C^{c}$ on $S_{1}$ should be positive and larger than the effect of $C^{n c}$ on $S_{1} \cdot{ }^{38}$ The rationale for this hypothesis is that cooperative works councils, due to reciprocity, are more likely to succeed in bargaining with the management - e.g., in terms of upgrading workers or assigning jobs to higher pay-grades - than noncooperative works councils. In other words, firms have paid for the cooperation

\footnotetext{
${ }^{36}$ The results of the sensitivity checks are available from the authors upon request.

${ }^{37}$ This type of works council serves as our reference group, so the corresponding dummy variable is excluded from equation (24).

${ }^{38}$ Just as in the previous subsections, the value 1 indexes establishments belonging to the works council regime.
} 
with the works council by leaving the workforce a larger share in the rent. ${ }^{39}$ Hence, a positive impact of cooperative works councils on the wage bill-to-total sales ratio would also support our view of $S=W / Y$ as a measure for rent-seeking activities. If, on the other hand, $S$ were a pure profitability indicator free from rent-seeking issues, we would rather expect a negative impact of cooperative works councils because, in this case, a good cooperation between management and works council should turn out to be profitability enhancing.

Our basic regression model for the effect of the degree of works council cooperation can be written as

$$
S_{1 i t}=\alpha_{1} N_{i t}+X_{i t} \beta_{1}+\lambda_{n c} C_{i t}^{n c}+\lambda_{c} C_{i t}^{c}+\mu_{1 i}+\xi_{1 t}+u_{1 i t} .
$$

Since $C^{n c}$ and $C^{c}$ are only observed in one of the panel waves (2006), we cannot apply the conventional strategies to control for unobserved establishment heterogeneity and selectivity. In order to account for unobserved establishment characteristics, we therefore apply a two-step estimation procedure in analogy to the approaches proposed, for example, in Hirsch (1990) or Black and Lynch (2001). ${ }^{40}$ According to these approaches, we regress, in a first step, our outcome variable $S$ on $N$ and other time varying input factors $X^{v}$ available for the entire observation period 2001 to 2008. Thereby, we also control for sectoral and cyclical fluctuations. Our first-step regression equation can therefore be written as

$$
S_{i t}=\alpha N_{i t}+X_{i t}^{v} \beta+\mu_{i}+\xi_{t}+u_{i t}
$$

From this equation we calculate the establishment-specific, time-invariant component of the residual, i.e., $\hat{\mu}_{i}$. This establishment fixed effect measures whether an individual $S_{i}$ structurally exceeds or falls below the wage bill-to-total sales ratio of other establishments. In the second step, we regress $\hat{\mu}_{i} \mid C_{i}=1$ on the remaining

\footnotetext{
${ }^{39}$ There even exist extreme cases where the top management of a firm bribes the members of the works council to achieve cooperation. For example, in 2007 Volkswagen (VW) top manager Peter Hartz was convicted of misappropriation since he had used 2.6 million euro of VW to corrupt the VW works council.

${ }^{40}$ Similar to our research question, Hirsch (1990) investigates the rent-seeking effects of union coverage, while Black and Lynch (2001) examine the productivity effects of innovative workplace practices and information technology.
} 
(quasi-fixed) explanatory variables in $X$, i.e., $X^{f}$ and the cooperation dummies $C^{n c}$ and $C^{c}$.

It is evident from equation (24) that our current regression approach is restricted to establishments with a works council and thus excludes establishments without a works council. Hence, apart from unobserved heterogeneity we must also take the selectivity problem into account. We additionally control for a potential selectivity bias by adding inverse Mill's ratio calculated from a standard cross-sectional endogenous switching regression model in analogy to (14), (15), and (16) as a selectivity correction term to the set of explanatory variables. ${ }^{41}$ As a whole, the second stage of our two-step regression approach can therefore be expressed as

$$
E\left(\mu_{i} \mid C_{i}=1\right)=X_{i}^{f} \beta_{1}+\lambda_{n c} C_{i}^{n c}+\lambda_{c} C_{i}^{c}+\sigma_{\tilde{\varepsilon}, 1} \frac{\phi\left(\delta N_{i}+Z_{i} \gamma\right)}{\Phi\left(\delta N_{i}+Z_{i} \gamma\right)}
$$

where $\sigma_{\tilde{\varepsilon}, 1}=\sigma_{\tilde{\varepsilon}, \tilde{u}_{1}} \cdot \phi(\cdot)$ and $\Phi(\cdot)$ represent the density and the distribution function of the standard normal distribution, and $\phi(\cdot) / \Phi(\cdot)$ is inverse Mill's ratio (or normal hazard function). ${ }^{42} \quad \lambda_{c}>0$ and $\lambda_{c}>\lambda_{n c}$ would support our view of $S$ as a measure for rent-seeking intensity. The corresponding parameter estimates (with and without selectivity correction) are displayed in Table $2 .{ }^{43}$

[Insert Table 2 about here]

The estimates confirm our expectations, i.e., works councils maintaining a cooperative relationship with the management tend to increase the establishment's wage bill-to-total sales ratio. $\lambda_{c}$ is positive and significant relative to the reference group, while $\lambda_{n c}$ measuring the corresponding impact for non-cooperative works councils is insignificant. Moreover, a Wald test confirms that $\lambda_{c}>\lambda_{n c}$. These results hold irrespective of selectivity correction. Note, however, that the coefficient

\footnotetext{
${ }^{41}$ Similar to the proceeding in Subsection 6.2 we use the establishment age and the exployment expectations dummy variable as exclusion restrictions in the selection equation.

${ }^{42}$ For a similar procedure see Zwick (2005) who examines the productivity effects of continuous training, as well as Zwick (2004) and Mueller (2009) who focus on the productivity effects of employee participation or works councils in Germany.

${ }^{43}$ The first-stage estimates according to equation (25) are displayed in Table 4 in the appendix. The estimates of the remaining second-stage control variables are available from the authors upon request.
} 
for inverse Mill's ratio $\sigma_{\tilde{\varepsilon}, 1}$ is insignificant which is consistent with the estimate of $\rho_{\tilde{\varepsilon}, 1}$ in the previous subsection.

To sum up, when it is just the cooperative works councils that contribute to increasing the workers' share in establishment output, we can interpret this finding in terms of rent seeking, i.e., cooperative works councils are likely to succeed in redistributing rents from the employer to the workers. Hence, we can state that this result is in line with our estimates in the previous subsection. As a consequence, our interpretation of the wage bill-to-total sales ratio as an indicator for rentseeking activities and thus our conclusions in terms of the examined rent-seeking effects gain additional support through the estimates in this subsection.

\section{Conclusions}

When analyzing establishment size and internal rent seeking, one might at first sight suppose that the employer prefers a small establishment size to limit the intensity of internal politicking by reducing the number of rent seekers (quantity effect). However, the theoretical results have shown that a large establishment size may be beneficial for the employer, if individual rent seekers are discouraged by a large number of opponents (discouragement effect). Since the employer himself engages in the contest, the discouragement effect would reduce his own rent-seeking expenditures. In addition, the employer will not exclusively choose establishment size in order to control rent-seeking behavior. Our model has revealed that the smaller the degree of contract incompleteness, the more the employer will focus on technological aspects when choosing the size of the workforce.

We have shown that the introduction of a works council leads to efficient establishment size in the theoretical model. A works council allows the workers to coordinate individual behavior in the rent-seeking contest. In that case, the employer competes against a single collective player, leading to a disentangling of rent-seeking and production issues. Consequently, the employer is only concerned with production technology and implements efficient establishment size. However, the employer does not necessarily benefit from a works council. He will only benefit if restored production efficiency and a higher share in the rent outweigh his larger 
rent-seeking expenditures caused by more aggressive behavior in the contest.

The last section offers an empirical analysis that tests the relevance of the quantity and the discouragement effects as well as the role of works councils in rent seeking. The econometric results point out that the discouragement effect dominates the quantity effect in establishments without a works council. As theoretically predicted, works councils override both effects, so that the impact of establishment size on rent-seeking intensity is no longer significant. This finding is also intuitively plausible. When a works council is installed, the employer can no longer use establishment size to influence the rent-seeking behavior of the workforce. Instead, the employer will focus on production efficiency to maximize profits. Higher profits increase the employer's income both from production that is protected by contracts and from the rent-seeking contest. Note that the advantage of disentangling rent-seeking and production issues is also applicable to local unions in the United States or other countries since the theoretical argument of our model does not depend on institutional details that are specific to works councils. Even the employer may benefit from a works council or local union as a single collective opponent in the rent-seeking contest, particularly if this opponent happens to be weak because of internal agency problems that prevent perfect worker coordination.

\section{References}

Abdulai, Awudu and Hendrik Tietje. 2007. "Estimating Technical Efficiency under Unobserved Heterogeneity with Stochastic Frontier Models: Application to Northern German Dairy Farms." European Review of Agricultural Economics, Vol. 34, No. 3, pp. 393-416.

Addison, John T. 2009. The Economics of Codetermination. Lessons from the German Experience, New York.

Addison, John T., Schank, Thorsten, Schnabel, Claus and Joachim Wagner. 2006. "Works Councils in the Production Process." Schmollers Jahrbuch, Vol. 126, No. 2, pp. 251-283. 
Addison, John T., Schnabel, Claus and Joachim Wagner. 1997. "On the Determinants of Mandatory Works Councils in Germany." Industrial Relations, Vol. 36, No. 4, pp. 419-445.

Addison, John T., Schnabel, Claus and Joachim Wagner. 2001. "Works Councils in Germany: Their Effects on Establishment Performance." Oxford Economic Papers, Vol. 53, No. 4, pp. 659-694.

Addison, John T., Siebert, W. Stanley, Wagner, Joachim and Xiangdong Wei. 2000. "Worker Participation and Firm Performance: Evidence from Germany and Britain." British Journal of Industrial Relations, Vol. 38, No. 1, pp. 7-48.

Beatty, Anne, Liao, Scott and Joseph Weber. 2010. "Financial Reporting Quality, Private Information, Monitoring, and the Lease-versus-Buy Decision." Accounting Review, Vol. 85, No. 4, pp. 1215-1238.

Beckmann, Michael, Föhr, Silvia and Matthias Kräkel. 2010. "Rent Seeking, Employment Security, and Works Councils: Theory and Evidence for Germany." Schmalenbach Business Review, Vol. 62, No. 1, pp. 2-40.

Black, S. and L. Lynch. 2001. "How to Compete: The Impact of Workplace Practices and Information Technology on Productivity." Review of Economics and Statistics, Vol. 83, No. 3, pp. 434-445.

Burgert, Derik. 2006. "The Impact of German Job Protection Legislation on Job Creation in Small Establishments." Applied Economics Quarterly, Vol. 52, pp. 123-139.

Dustmann, Christian and Christoph M. Schmidt. 2000. "The Wage Performance of Immigrant Women: Full-Time Jobs, Part-Time Jobs, and the Role of Selection." IZA Discussion Paper No. 233.

Fister, Todd. 2002. "Estimating Returns to Managers from Employee Unionization." In Paula B. Voos, ed., Industrial Relations Research Association Series: Proceedings of the 54th Annual Meeting, pp. 25-31. University of Illinois at Urbana-Champaign. 
Fitzenberger, Bernd, Kohn, Karsten and Qingwei Wang. 2011. "The Erosion of Union Membership in Germany: Determinants, Densities, Decompositions." Journal of Population Economics, Vol. 24, No. 1, pp. 141-165.

Fitzroy, Felix R. and Kornelius Kraft. 1987. "Efficiency and Internal Organization: Works Councils in West German Firms." Economica, Vol. 54, No. 216, pp. $493-504$.

Freeman, Richard B. and Edward P. Lazear. 1995. "An Economic Analysis of Works Councils." In Joel Rogers and Wolfgang Streeck, eds., Works Councils: Consultation, Representation, and Cooperation in Industrial Relations, pp. 27-50. Chicago/London.

Frick, Bernd and Iris Möller. 2003. "Mandated Works Councils and Firm Performance: Labor Productivity and Personnel Turnover in German Establishments." Schmollers Jahrbuch, Vol. 123, No. 3, pp. 423-454.

Gibbons, Robert. 2005. "Four Formal(izable) Theories of the Firm?." Journal of Economic Behavior and Organization, Vol. 58, No. 2, pp. 200-245.

Hirsch, Barry T. 1990. "Market Structure, Union Rent Seeking, and Firm Profitability." Economics Letters, Vol. 32, No. 1, pp. 75-79.

Hirschman, Albert O. 1970. Exit, Voice and Loyalty. Cambridge (Mass.)/ London.

Holmström, Bengt, and John Roberts. 1998. "The Boundaries of the Firm Revisited." Journal of Economics Perspectives, Vol. 12, No. 4, pp. 73-94.

Inderst, Roman, Müller, Holger H. and Karl Wärneryd. 2007. "Distributional Conflict in Organizations." European Economic Review, Vol. 51, No. 2, pp. 385-402.

Jirjahn, Uwe. 2009. "The Introduction of Works Councils in German Establishments - Rent Seeking or Rent Protection?." British Journal of Industrial Relations, Vol. 47, No. 3, pp. 521-545. 
Jones, Andrew M., Rice, Nigel, Bago d'Uva, Teresa and Silvia Balia. 2007. Applied Health Economics. New York.

Koller, Lena. 2010. Ökonomische Auswirkungen arbeits- und sozialrechtlicher Schwellenwerte. Frankfurt a.M.

Koller, Lena, Schnabel, Claus and Joachim Wagner. 2008. "Freistellung von Betriebsräten - Eine Beschäftigungsbremse?." Journal for Labour Market Research, Vol. 41, pp. 305-326.

Konrad, Kai A. 2002. "Investment in the Absence of Property Rights: The Role of Incumbency Advantages." European Economic Review, Vol. 46, No. 8, pp. 1521-1537.

Konrad, Kai A. 2004. "Bidding in Hierarchies." European Economic Review, Vol. 48, No. 6, pp. 1301-1308.

Kräkel, Matthias. 2008. "On Adverse Selection of Technologies." Journal of Institutional and Theoretical Economics, Vol. 164, No. 2, pp. 343-355.

Kraft, Kornelius and Julia Lang. 2008. "The Causes and Consequences of Adopting a Works Council." Jahrbücher für Nationalökonomie und Statistik, Vol. 228, No. 5+6, pp. 512-532.

Lindbeck, Assar and Dennis J. Snower. 1987. "Efficiency Wages versus Insiders and Outsiders." European Economic Review, Vol. 31, No. 1-2, pp. 407-416.

Lindbeck, Assar and Dennis J. Snower. 1988. "Cooperation, Harassment, and Involuntary Unemployment: An Insider-Outsider Approach.” American Economic Review, Vol. 78, No. 1, pp. 167-188.

Lokshin, Michael and Kathleen Beegle. 2011. "Forgone Earnings from Smoking: Evidence for a Developing Country." In Solomon W. Polachek and Konstantinos Tatsiramos, eds., Research in Labor Economics, pp. 209-238. Bingley, UK. 
Lokshin, Michael and Zurab Sajaia. 2004. "Maximum Likelihood Estimation of Endogenous Switching Regression Models." Stata Journal, Vol. 4, No. 3, pp. 282-289.

Maddala, Gangadharrao S. 1983. Limited-Dependent and Qualitative Variables in Econometrics, Cambridge.

Masten, Scott E. 1986. "Institutional Choice and the Organization of Production: The Make-or-Buy Decision." Journal of Institutional and Theoretical Economics, Vol. 142, No. 3, pp. 493-509.

Mueller, Steffen. 2009. "The Productivity Effect of Non-Union Representation." BGPE Discussion Paper No. 74.

Mundlak, Yair. 1978. "On the Pooling of Time Series and Cross-Section Data." Econometrica, Vol. 46, No. 1, pp. 69-85.

Nti, Kofi O. 1997. "Comparative Statics of Contests and Rent-Seeking Games." International Economic Review, Vol. 38, No. 1, pp. 43-59.

Rogers, Joel and Wolfgang Streeck (eds.). 1995. Works Councils: Consultation, Representation, and Cooperation in Industrial Relations, Chicago/ London.

Simon, Herbert A. 1951. "A Formal Theory of the Employment Relationship." Econometrica, Vol. 19, No. 3, pp. 293-305.

Skaperdas, Stergios. 1996. "Contest Success Functions." Economic Theory, Vol. 7, No. 2, pp. 283-290.

Verick, Sher. 2004. "Threshold Effects of Dismissal Protection Legislation in Germany." IZA Discussion Paper No. 991.

Wagner, Joachim, Schnabel, Claus and Arnd Kölling. 2001. "Wirken Schwellenwerte im deutschen Arbeitsrecht als Bremse für die Arbeitsplatzbeschaffung in Kleinbetrieben?." In Detlev Ehrig and Peter Kalmbach, eds., Weniger Arbeitslose - aber wie? Gegen Dogmen in der Arbeitsmarkt- und Beschäftigungspolitik, pp. 177-198. Marburg. 
Wärneryd, Karl. 2001. "Replicating Contests." Economics Letters, Vol. 71, No. 3, pp. 323-327.

Zwick, Thomas. 2004. "Employee Participation and Productivity." Labour Economics, Vol. 11, No. 6, pp. 715-740.

Zwick, Thomas. 2005. "Continuing Vocational Training Forms and Establishment Productivity in Germany." German Economic Review, Vol. 6, No. 2, pp. $155-184$.

\section{Appendix}

\section{Proof of Corollary 1:}

In case of a power impact function (2) equilibrium expenditures $a^{*}$ are given by $a^{*}=\beta N(1-\alpha) \pi(N) /(1+N)^{2}$. Using $A^{\prime}(\cdot)=\beta$, condition $(7)$ boils down to

$$
\alpha \pi^{\prime}\left(N^{*}\right)=\frac{1-\alpha}{1+N^{*}}\left[\frac{\pi\left(N^{*}\right)}{1+N^{*}}\left(1-\beta \frac{N^{*}-1}{1+N^{*}}\right)-\pi^{\prime}\left(N^{*}\right)\left(1-\frac{\beta N^{*}}{1+N^{*}}\right)\right] .
$$

Note that both $\left(1-\beta \frac{N-1}{1+N}\right)$ and $\left(1-\frac{\beta N}{(1+N)}\right)$ are positive since $\beta \in(0,1)$. If $\pi^{\prime}\left(N^{*}\right)$ on the right-hand side of the last equation were negative, we would have a contradiction with the left-hand side. Therefore, we must have $\pi^{\prime}\left(N^{*}\right)>0$ implying $N^{*}<N^{F B}$.

Proof of Proposition 2:

Given a power impact function, optimal establishment size is described by

$$
\begin{aligned}
\Psi:=\alpha \pi^{\prime}\left(N^{*}\right)-\frac{1-\alpha}{1+N^{*}}[ & \left(\frac{\pi\left(N^{*}\right)}{1+N^{*}}-\pi^{\prime}\left(N^{*}\right)\right) \\
& \left.-\beta\left(\frac{\pi\left(N^{*}\right)\left(N^{*}-1\right)}{\left(1+N^{*}\right)^{2}}-\frac{\pi^{\prime}\left(N^{*}\right) N^{*}}{\left(1+N^{*}\right)}\right)\right]=0 .
\end{aligned}
$$

Implicit differentiation gives

$$
\frac{\partial N^{*}}{\partial \theta}=\frac{\alpha Y^{\prime}\left(N^{*}\right)-\frac{1-\alpha}{1+N^{*}}\left[\left(\frac{Y\left(N^{*}\right)}{1+N^{*}}-Y^{\prime}\left(N^{*}\right)\right)-\beta\left(\frac{Y\left(N^{*}\right)\left(N^{*}-1\right)}{\left(1+N^{*}\right)^{2}}-\frac{Y^{\prime}\left(N^{*}\right) N^{*}}{\left(1+N^{*}\right)}\right)\right]}{-\partial \Psi / \partial N^{*}}
$$


since $\partial \pi(N) / \partial \theta=Y(N)$ and $\partial \pi^{\prime}(N) / \partial \theta=Y^{\prime}(N)$. The denominator is positive since, by assumption, the employer's second-order condition at stage 2 of the game is always satisfied. Note that

$$
\frac{Y\left(N^{*}\right)}{1+N^{*}}-Y^{\prime}\left(N^{*}\right)>\frac{Y\left(N^{*}\right)\left(N^{*}-1\right)}{\left(1+N^{*}\right)^{2}}-\frac{Y^{\prime}\left(N^{*}\right) N^{*}}{\left(1+N^{*}\right)} \Leftrightarrow \frac{2}{N+1} Y\left(N^{*}\right)>Y^{\prime}\left(N^{*}\right)
$$

is always satisfied since $\frac{2}{N+1}>\frac{1}{N}$, and $\frac{Y(N)}{N}>Y^{\prime}(N)$ must hold because $Y(N)$ is concave. Hence, we must differentiate between three possible constellations for the numerator of (A1): (i) If both terms in parentheses, $\frac{Y\left(N^{*}\right)}{1+N^{*}}-Y^{\prime}\left(N^{*}\right)$ and $\frac{Y\left(N^{*}\right)\left(N^{*}-1\right)}{\left(1+N^{*}\right)^{2}}-\frac{Y^{\prime}\left(N^{*}\right) N^{*}}{\left(1+N^{*}\right)}$, are positive the whole expression in square brackets will be positive as $\beta \in(0,1)$. If the first term in parentheses is positive and the second one negative, again the expression in square brackets will be positive. If both terms in parentheses are negative (i.e., $\frac{Y\left(N^{*}\right)}{1+N^{*}}<Y^{\prime}\left(N^{*}\right)$ ), the expression in square brackets will be negative if and only if $\beta$ is smaller than the cut-off $\bar{\beta}:=\left(Y^{\prime}\left(N^{*}\right)-\frac{Y\left(N^{*}\right)}{1+N^{*}}\right) /\left(\frac{Y^{\prime}\left(N^{*}\right) N^{*}}{\left(1+N^{*}\right)}-\frac{Y\left(N^{*}\right)\left(N^{*}-1\right)}{\left(1+N^{*}\right)^{2}}\right)$.

\section{Proof of Proposition 3:}

The first-order condition

$$
\frac{\partial u_{E}\left(N, a_{E}^{*}\right)}{\partial N}=\left[\frac{1+\alpha}{2}-A^{\prime}\left(\frac{(1-\alpha) \pi(N)}{4}\right) \frac{(1-\alpha)}{4}\right] \pi^{\prime}(N)=0
$$

yields two sets of stationary points. The first set contains all $N_{1}$ with $\frac{2(1+\alpha)}{1-\alpha}=$ $A^{\prime}\left(\frac{(1-\alpha) \pi\left(N_{1}\right)}{4}\right)$, whereas the second one is a singleton consisting of $N_{2}=N^{F B}$ with $\pi^{\prime}\left(N_{2}\right)=0$. Optimal establishment size must satisfy

$$
\begin{aligned}
\frac{\partial^{2} u_{E}\left(N, a_{E}^{*}\right)}{\partial N^{2}} & =-A^{\prime \prime}\left(\frac{(1-\alpha) \pi(N)}{4}\right) \frac{(1-\alpha)^{2}\left[\pi^{\prime}(N)\right]^{2}}{16} \\
& +\left[\frac{2(1+\alpha)}{1-\alpha}-A^{\prime}\left(\frac{(1-\alpha) \pi(N)}{4}\right)\right] \frac{(1-\alpha) \pi^{\prime \prime}(N)}{4}<0
\end{aligned}
$$

to describe a maximum. Obviously, $\partial^{2} u_{E}\left(N, a_{E}^{*}\right) /\left.\partial N^{2}\right|_{N=N_{1}}>0$ since $A^{\prime \prime}(\cdot)<0$ due to the concavity of $A(\cdot)$. Since all $N_{1}$ correspond to a minimum and $u_{E}\left(N, a_{E}^{*}\right)$ is continuous (when treating $N$ as a continuous variable), $N_{2}$ must describe a maximum. 


\section{Proof of Proposition 6:}

Given (2), without works council, $E$ optimally spends $a^{*}-\Delta=\beta N^{*}(1-\alpha)$ $\pi\left(N^{*}\right) /\left(1+N^{*}\right)^{2}-\Delta$ in the contest (with $N^{*}<N^{F B}$ according to Corollary 1). When comparing $a^{*}-\Delta$ to $a_{E}^{*}=\beta \gamma^{* \beta}(1-\alpha) \pi\left(N^{F B}\right) /\left(1+\gamma^{* \beta}\right)^{2}-\Delta_{E}$ we have to take account of the facts that $\pi\left(N^{F B}\right)>\pi\left(N^{*}\right)$, and that $\gamma^{* \beta} /\left(1+\gamma^{* \beta}\right)^{2}>$ $N^{*} /\left(1+N^{*}\right)^{2}$ if and only if $\gamma^{*}$ is sufficiently large.

Recall that without works council $E$ realizes utility

$$
u_{E}\left(N^{*}\right)=\left(\alpha+(1-\alpha) \frac{1+(1-\beta) N^{*}}{\left(N^{*}+1\right)^{2}}\right) \pi\left(N^{*}\right)+\Delta
$$

whereas with works council his utility amounts to $u_{E}\left(N^{F B} ; \gamma^{*}\right)$. Since $\pi\left(N^{F B}\right)>$ $\pi\left(N^{*}\right), \gamma^{* \beta}<N^{*}$ and the expression $[1+(1-\beta) x] /(x+1)^{2}$ is monotonically decreasing in $x$, we immediately obtain $u_{E}\left(N^{F B} ; \gamma^{*}\right)>u_{E}\left(N^{*}\right)$ for $\Delta_{E}=\Delta$. 
Table 1: Quantity effect vs. discouragement effect

\begin{tabular}{|c|c|c|c|c|c|c|}
\hline \multirow[t]{2}{*}{ Model } & \multicolumn{2}{|c|}{$\begin{array}{l}\text { Fixed effects model } \\
\quad(12),(13)\end{array}$} & \multicolumn{4}{|c|}{$\begin{array}{l}\text { Endogenous switching regression model } \\
(20),(21),(22)\end{array}$} \\
\hline & $C=0$ & $C=1$ & $C=0$ & $C=1$ & $C=0$ & $C=1$ \\
\hline$N$ & $\begin{array}{c}-0.143^{* * *} \\
(0.005)\end{array}$ & $\begin{array}{c}-0.001 \\
(0.896)\end{array}$ & $\begin{array}{c}-0.092^{* *} \\
(0.048)\end{array}$ & $\begin{array}{c}-0.000 \\
(0.966)\end{array}$ & $\begin{array}{c}-0.119^{* *} \\
(0.019)\end{array}$ & $\begin{array}{c}-0.002 \\
(0.852)\end{array}$ \\
\hline$\rho_{\tilde{\varepsilon}, 0}$ & & & $\begin{array}{l}0.121^{* * *} \\
{[0.026]}\end{array}$ & & $\begin{array}{l}0.136^{* * *} \\
{[0.027]}\end{array}$ & \\
\hline$\rho_{\tilde{\varepsilon}, 1}$ & & & & $\begin{array}{c}0.002 \\
{[0.033]}\end{array}$ & & $\begin{array}{c}0.027 \\
{[0.035]}\end{array}$ \\
\hline$\chi^{2}$-test & of indepen & dent equat & ions & $\begin{array}{l}21.01^{* * *} \\
(0.000)\end{array}$ & & $\begin{array}{l}25.13^{* * *} \\
(0.000)\end{array}$ \\
\hline$\chi^{2}$-test & of $\alpha_{0}=\alpha_{1}$ & & & $\begin{array}{c}3.56^{*} \\
(0.059)\end{array}$ & & $\begin{array}{r}5.13^{* *} \\
(0.023)\end{array}$ \\
\hline \multicolumn{7}{|c|}{$\chi^{2}$-test of irrelevant exclusion restrictions } \\
\hline & & & & $\begin{array}{c}166.18^{* * *} \\
(0.000)\end{array}$ & & $\begin{array}{r}172.30^{* * *} \\
(0.000)\end{array}$ \\
\hline$\chi^{2}$-test & of exogene & ous exclus & ion restrict & $\begin{array}{l}\text { ions } \\
\qquad .218 \\
(0.640)\end{array}$ & & $\begin{array}{c}0.455 \\
(0.499)\end{array}$ \\
\hline$\chi^{2}$-test & of insignifi & cant contr & $\begin{array}{c}\text { ols for corr } \\
320.13^{* * *} \\
(0.000)\end{array}$ & $\begin{array}{l}\text { elated fixec } \\
235.65^{* * *} \\
\quad(0.000)\end{array}$ & $\begin{array}{l}\text { d effects } \\
299.00^{* * *} \\
(0.000)\end{array}$ & $\begin{array}{c}249.47^{* * *} \\
(0.000)\end{array}$ \\
\hline$n_{o b s}$ & 35,632 & 18,941 & & 54,573 & & 50,413 \\
\hline$n_{\text {est }}$ & 12,401 & 6,709 & & 18,229 & & 17,348 \\
\hline
\end{tabular}

Note: ${ }^{*} /{ }^{* *} /{ }^{* * *}$ denotes significance at the $10 / 5 / 1 \%$ level. The estimated coefficients for $N$ are multiplied with 1,000. The values in ( ) represent $p$-values calculated on the basis of clusterrobust standard errors that cluster on the individual establishment to correct for the potential correlation of the error terms over time. The values in [ ] for $\rho_{\tilde{\varepsilon}, 0}$ and $\rho_{\tilde{\varepsilon}, 1}$ represent the respective standard errors. The $\chi^{2}$-test of exogeneous instruments is a (modified) Sargan test that reports $p$-values calculated on the basis of conventional standard errors. $n_{\text {obs }}$ is sample size. $n_{\text {est }}$ is the number of establishments. All model specifications additionally control for technological innovations (technical state of the technologies in use, expansion investments per capita), the structure of the workforce (skilled workers, female workers, fixed-term workers, part-time workers, apprentices), export shares, and include dummy variables for collective wage setting, extra payments beyond the wage bargaining level, foreign ownership, private companies, independent firms, sector affiliation, location and time.

Source: IAB Establishment Panel 2001-2008, own calculations. 
Table 2: Effects of cooperative and non-cooperative works councils

\begin{tabular}{lcc}
\hline Model & $\begin{array}{c}\text { Two-step approach, } \\
\text { equation }(26) \text { without } \\
\text { selectivity correction }\end{array}$ & $\begin{array}{l}\text { Two-step approach, } \\
\text { selectivity corrected, } \\
\text { equation }(26)\end{array}$ \\
\hline$C^{n c}$ & -0.011 & -0.011 \\
& $(0.358)$ & $(0.373)$ \\
$C^{c}$ & $0.022^{* * *}$ & $0.022^{* * *}$ \\
& $(0.004)$ & $(0.005)$ \\
$\phi(\cdot) / \Phi(\cdot)$ & & 0.021 \\
& & $(0.204)$ \\
\hline$F$-test of $\lambda_{n c}=\lambda_{c}$ & $5.98^{* *}$ & $5.65^{* *}$ \\
& $(0.014)$ & $(0.017)$ \\
$\chi^{2}$-test of irrelevant instruments & $31.11^{* * *}$ \\
& & $(0.000)$ \\
$\chi^{2}$-test of exogeneous instruments & 2.288 \\
& & $(0.130)$ \\
$n$ & 1,907 & 1,907 \\
\hline
\end{tabular}

Note: ${ }^{*} / *{ }^{* * *}$ denotes significance at the $10 / 5 / 1 \%$ level. The values in parentheses represent $p$-values calculated on the basis of heteroskedasticity-robust standard errors. The $\chi^{2}$-test of exogeneous instruments reports $p$-values calculated on the basis of conventional standard errors. It works similar to the Sargan test, i.e., at first the residuals estimated from equation (26) are regressed on the exclusion restrictions, the cooperation dummies and $X^{f}$. Then, the $p$-value of the resulting test statistic $n \cdot R^{2}$ is calculated from the $\chi^{2}$-distribution. $n$ is sample size. The first-stage specification (see Table 4 in the appendix) controls for input factors (i.e., establishment size, technological innovations and the structure of the workforce), sector affiliation and time. The second-stage specification additionally includes export shares as well as dummy variables for collective wage setting, extra payments beyond the wage bargaining level, foreign ownership, private companies, independent firms, sector affiliation, establishment size and location.

Source: IAB Establishment Panel 2001-2008, own calculations. 
Table 3: Definition of the variables and descriptive statistics

\begin{tabular}{|c|c|c|c|c|}
\hline Variable & Definition & Mean & Std.-dev. & Min-Max \\
\hline$S=W / Y$ & Wage bill-total sales ratio & 0.287 & 0.184 & $0.001-1$ \\
\hline$N$ & Number of employees & 152.27 & 506.25 & $5-19,671$ \\
\hline$C$ & $\begin{array}{l}\text { Dummy variable indicating whether } \\
\text { or not an establishment has a works } \\
\text { council }\end{array}$ & 0.347 & 0.476 & $0-1$ \\
\hline $\begin{array}{l}\text { Skilled work- } \\
\text { ers }\end{array}$ & $\begin{array}{l}\text { Share of skilled workers on the basis } \\
\text { of total workforce }(\%)\end{array}$ & 68.59 & 25.54 & $0-100$ \\
\hline $\begin{array}{l}\text { Fixed-term } \\
\text { workers }\end{array}$ & $\begin{array}{l}\text { Share of fixed-term workers on the } \\
\text { basis of total workforce }(\%)\end{array}$ & 5.04 & 12.04 & $0-100$ \\
\hline $\begin{array}{l}\text { Part-time } \\
\text { workers }\end{array}$ & $\begin{array}{l}\text { Share of part-time workers on the } \\
\text { basis of total workforce }(\%)\end{array}$ & 17.95 & 22.83 & $0-100$ \\
\hline Apprentices & $\begin{array}{l}\text { Share of apprentices on the basis of } \\
\text { total workforce }(\%)\end{array}$ & 5.62 & 9.12 & $0-100$ \\
\hline $\begin{array}{l}\text { Female } \\
\text { workers }\end{array}$ & $\begin{array}{l}\text { Share of female workers on the basis } \\
\text { of total workforce }(\%)\end{array}$ & 38.09 & 28.91 & $0-100$ \\
\hline $\begin{array}{l}\text { Technical } \\
\text { status }\end{array}$ & $\begin{array}{l}\text { Dummy variable calculated from an } \\
\text { ordinal variable } T S \text { ranging between } \\
1 \text { (technologies in use are out-of- } \\
\text { date) and } 5 \text { (technologies in use are } \\
\text { state-of-the-art); } 1 \text { if } T S \geq 4,0 \text { oth- } \\
\text { erwise }\end{array}$ & 0.677 & 0.467 & $0-1$ \\
\hline $\begin{array}{l}\text { Expansion } \\
\text { investments }\end{array}$ & $\begin{array}{l}\text { Natural logarithm of a firm's expan- } \\
\text { sion investments per capita }\end{array}$ & 2.92 & 7.70 & $-8.81-19.25$ \\
\hline Export share & $\begin{array}{l}\text { Export share on the basis of total } \\
\text { sales }(\%)\end{array}$ & 8.07 & 18.71 & $0-100$ \\
\hline Union & $\begin{array}{l}\text { Dummy variable indicating whether } \\
\text { or not an establishment commits to } \\
\text { collective wage bargaining at the in- } \\
\text { dustry or firm level }\end{array}$ & 0.527 & 0.499 & $0-1$ \\
\hline Extra pay & $\begin{array}{l}\text { Dummy variable indicating whether } \\
\text { or not an establishment pays wages } \\
\text { above the collective wage bargaining } \\
\text { level }\end{array}$ & 0.256 & 0.436 & $0-100$ \\
\hline $\begin{array}{l}\text { Private com- } \\
\text { pany }\end{array}$ & $\begin{array}{l}\text { Dummy variable indicating whether } \\
\text { or not an establishment is managed } \\
\text { under the legal form of a one-man } \\
\text { business or a business partnership }\end{array}$ & 0.263 & 0.440 & $0-1$ \\
\hline
\end{tabular}


Table 3: Definition of the variables and descriptive statistics; continued

\begin{tabular}{|c|c|c|c|c|}
\hline Variable & Definition & Mean & Std.-dev. & Min-Max \\
\hline $\begin{array}{l}\text { Foreign own- } \\
\text { ership }\end{array}$ & $\begin{array}{l}\text { Dummy variable indicating whether } \\
\text { or not an establishment has a non- } \\
\text { domestic owner }\end{array}$ & 0.061 & 0.240 & $0-1$ \\
\hline $\begin{array}{l}\text { Independent } \\
\text { company }\end{array}$ & $\begin{array}{l}\text { Dummy variable indicating whether } \\
\text { or not an establishment is autarkic }\end{array}$ & 0.749 & 0.433 & $0-1$ \\
\hline West & $\begin{array}{l}\text { Dummy variable indicating whether } \\
\text { or not an establishment is located in } \\
\text { West Germany }\end{array}$ & 0.620 & 0.485 & $0-1$ \\
\hline $\begin{array}{l}\text { Establishment } \\
\text { age }\end{array}$ & $\begin{array}{l}\text { Dummy variable indicating whether } \\
\text { or not an establishment has been } \\
\text { founded later than } 1990\end{array}$ & 0.434 & 0.495 & $0-1$ \\
\hline $\begin{array}{l}\text { Employment } \\
\text { expectations }\end{array}$ & $\begin{array}{l}\text { Dummy variable indicating whether } \\
\text { or not an establishment expects a } \\
\text { negative employment growth for the } \\
\text { next year }\end{array}$ & 0.167 & 0.373 & $0-1$ \\
\hline$C^{n c}$ & $\begin{array}{l}\text { Dummy variable indicating estab- } \\
\text { lishments that have to do with non- } \\
\text { cooperative works councils typically } \\
\text { opposing management decisions }\end{array}$ & 0.035 & 0.185 & $0-1$ \\
\hline$C^{c}$ & $\begin{array}{l}\text { Dummy variable indicating estab- } \\
\text { lishments that have to do with coop- } \\
\text { erative works councils typically sup- } \\
\text { porting management decisions }\end{array}$ & 0.224 & 0.417 & $0-1$ \\
\hline
\end{tabular}

Note: Number of observations: 54,573 (1,907 for $C^{n c}$ and $\left.C^{c}\right)$.

Source: IAB Establishment Panel 2001-2008, own calculations. 
Table 4: Control variables and first-stage regression estimates

\begin{tabular}{|c|c|c|c|c|}
\hline Variable & $\begin{array}{l}\text { Equation } \\
\qquad \begin{array}{l}(20) \\
C=0\end{array}\end{array}$ & $\begin{array}{l}\text { Equation } \\
\qquad \begin{array}{l}(21) \\
C=1\end{array}\end{array}$ & $\begin{array}{c}\text { Selection } \\
\text { equation } \\
\quad(22)\end{array}$ & $\begin{array}{c}\text { First-stage } \\
\text { estimates, } \\
\text { equation }(25)\end{array}$ \\
\hline$N$ & & & $0.612^{* * *}$ & -0.010 \\
\hline Skilled workers & $0.185^{* * *}$ & 0.107 & 0.231 & $0.154^{* * *}$ \\
\hline Fixed-term workers & $0.494^{* * *}$ & 0.344 & -0.931 & $0.458^{* * *}$ \\
\hline Part-time workers & -0.086 & 0.033 & -0.010 & -0.087 \\
\hline Apprentices & $-0.504^{* * *}$ & -0.023 & 0.576 & $-0.472^{* * *}$ \\
\hline Female workers & 0.034 & -0.074 & 0.254 & 0.010 \\
\hline Technical status & 1.250 & -1.014 & -2.831 & 0.519 \\
\hline Expansion investments & 0.175 & -0.183 & -0.489 & 0.034 \\
\hline Export share & $-0.214^{*}$ & $-0.190^{* *}$ & 0.648 & \\
\hline Union & 2.548 & -1.230 & $93.506^{* * *}$ & \\
\hline Extra pay & 1.439 & 1.954 & -19.708 & \\
\hline Private company & -6.816 & $-10.016^{*}$ & -8.721 & \\
\hline Foreign ownership & -0.429 & 5.427 & 64.766 & \\
\hline Independent company & 0.177 & -0.249 & -2.330 & \\
\hline West & -2.004 & $23.236^{* *}$ & 22.518 & \\
\hline $\begin{array}{l}\text { Establishment age } \\
\text { (within mean) }\end{array}$ & & & $-0.317^{* * *}$ & \\
\hline $\begin{array}{l}\text { Employment expectatior } \\
\quad \text { (within mean) }\end{array}$ & & & $0.533^{* * *}$ & \\
\hline Sector dummies & yes & yes & yes & yes \\
\hline Time dummies & yes & yes & yes & yes \\
\hline Within means & yes & yes & yes & no \\
\hline Constant & $0.198^{* * *}$ & $0.224^{* * *}$ & $-0.712^{* * *}$ & $0.292^{* * *}$ \\
\hline
\end{tabular}

Note: ${ }^{*} /{ }^{* *} /{ }^{* * *}$ denotes significance at the $10 / 5 / 1 \%$ level. Standard errors are omitted in order to save space. All coefficients are multiplied by 1,000 . This holds except for the constant terms and the instruments. Sample size is 54,573 . The number of establishments is 18,229

Source: IAB Establishment Panel 2001-2008, own calculations. 